Illinois State University

ISU ReD: Research and eData

Theses and Dissertations

$3-25-2019$

\title{
Gender and Persistence in STEM Careers: Predictors and Barriers
}

Margaret Rose Christie

Illinois State University, margaretrchristie@gmail.com

Follow this and additional works at: https://ir.library.illinoisstate.edu/etd

Part of the Psychology Commons

\section{Recommended Citation}

Christie, Margaret Rose, "Gender and Persistence in STEM Careers: Predictors and Barriers" (2019).

Theses and Dissertations. 1254.

https://ir.library.illinoisstate.edu/etd/1254

This Dissertation is brought to you for free and open access by ISU ReD: Research and eData. It has been accepted for inclusion in Theses and Dissertations by an authorized administrator of ISU ReD: Research and eData. For more information, please contact ISUReD@ilstu.edu. 


\section{GENDER AND PERSISTENCE IN STEM CAREERS: \\ PREDICTORS AND BARRIERS}

\section{MARGARET ROSE CHRISTIE}

\section{Pages}

In recent years, a great deal of emphasis has been placed on increasing students' interest in math and science. Specifically, interest in science, technology, engineering, and math (STEM) has been low among students in the United States, and interest seems to be lower among girls than boys. Additionally, increased emphasis has been placed on increasing female representation in STEM careers, as numbers of women in these fields remains disproportionately low compared to men. A variety of factors have been found to increase young people's interest in STEM, including parent and teacher factors, informal STEM experiences, self-efficacy in math and science, and individual differences such as curiosity and persistence. Previous research also indicates, however, that women may face specific barriers in STEM training related to their gender. The current study was an attempt to examine how predictors of STEM interest relate to each other and serve as predictors of pursuing a career in STEM. Further, the current study examined how pathways between these variables differ by gender. Finally, the current study explored the barriers experienced by students pursuing careers in STEM in an attempt to identify factors that deter women from entering these professions. For both men and women parental educational involvement predicted higher frequency of informal STEM learning experiences and lower ratings of persistence. For men only, parental educational involvement predicted higher curiosity and higher curiosity predicted lower persistence. For both men and women, higher 
frequency of informal science experiences predicted higher self-ratings of curiosity. For women only, frequency of informal science learning experiences in childhood was predictive of higher STEM self-efficacy. For both men and women, positive math and science high school teacher influence predicted higher curiosity as well as higher STEM self-efficacy. For women, math and science teacher influence was also predictive of higher likelihood of career selection involving STEM, whereas for men only, childhood informal science learning experiences were predictive of STEM career aspirations. Lastly, higher likelihood of STEM career aspirations was predicted by higher ratings of STEM self-efficacy for both men and women. Exploratory models examining the influence of inquiry-based learning (IBL) experiences in high school science classrooms indicated that IBL predicted higher curiosity, STEM self-efficacy, and aspirations to pursue a STEM career for both men and women. For women only, higher frequency of IBL in high school was predictive of lower self-ratings of persistence. This study adds to the current literature examining predictors of STEM career choice and explains how parental and family factors, school factors, and individual differences interact to explain differential pathways to STEM career interest for men and women.

KEYWORDS: STEM, Career choice, Gender, Self-efficacy, Inquiry-based learning 


\title{
GENDER AND PERSISTENCE IN STEM CAREERS: \\ PREDICTORS AND BARRIERS
}

\author{
MARGARET ROSE CHRISTIE
}

A Dissertation Submitted in Partial

Fulfillment of the Requirements

for the Degree of

DOCTOR OF PHILOSOPHY

Department of Psychology

ILLINOIS STATE UNIVERSITY 
(C) 2020 Margaret Rose Christie 


\title{
GENDER AND PERSISTENCE IN STEM CAREERS:
}

PREDICTORS AND BARRIERS

\author{
MARGARET ROSE CHRISTIE
}

COMMITTEE MEMBERS:

Corinne Zimmerman, Chair

Rebekka Darner

Matthew Hesson-McInnis

Jeffrey Kahn 


\section{ACKNOWLEDGMENTS}

I would like to thank my chair, Dr. Corinne Zimmerman, for her consistent support and guidance throughout my graduate education. I would like to thank my committee, Dr. Matthew Hesson-McInnis, Dr. Jef Kahn, and Dr. Rebekka Darner for their insight and encouragement on this project. I thank Jillian Reiher for her mentorship and assistance with the dissertation process. I would like to recognize Illinois State University's Department of Psychology and Graduate School. I thank participants for their time and contribution to research. In addition to the individuals listed above, I would like to thank my friends and family for their enthusiasm and support for me while I pursued my doctoral degree.

M. R. C. 


\section{CONTENTS}

Page

ACKNOWLEDGMENTS

CONTENTS

FIGURES Vii

CHAPTER I: INTRODUCTION 1

Science Interest and Gender 3

Parental Influence on Gendered Science Interest 3

Informal Science Experiences $\quad 5$

$\begin{array}{lr}\text { Predictors of STEM Career Aspirations } & 6\end{array}$

$\begin{array}{lr}\text { Parental Influence } & 6\end{array}$

$\begin{array}{ll}\text { Childhood Experiences } & 7\end{array}$

$\begin{array}{ll}\text { Teacher and School Influence } & 9\end{array}$

$\begin{array}{ll}\text { Teacher relationships and support } & 9\end{array}$

$\begin{array}{ll}\text { Teaching methods } & 10\end{array}$

$\begin{array}{ll}\text { Individual Differences } & 11\end{array}$

$\begin{array}{lr}\text { Persistence } & 11\end{array}$

$\begin{array}{ll}\text { Curiosity } & 14\end{array}$

$\begin{array}{ll}\text { Math and Science Self-Efficacy } & 16\end{array}$

$\begin{array}{lr}\text { Self-efficacy and Academic Achievement } & 17\end{array}$

$\begin{array}{lr}\text { Teacher Support and Self-efficacy } & 18\end{array}$

Gender Differences in Math and Science Self-efficacy 19

$\begin{array}{ll}\text { Self-efficacy and Persistence } & 20\end{array}$ 
$\begin{array}{ll}\text { Social Barriers } & 21\end{array}$

$\begin{array}{ll}\text { Gender role socialization } & 22\end{array}$

$\begin{array}{ll}\text { Gender stereotypes } & 23\end{array}$

$\begin{array}{ll}\text { Intelligence } & 23\end{array}$

Rationality and emotion $\quad 24$

Lack of female role models $\quad 24$

$\begin{array}{ll}\text { Microaggressions } & 25\end{array}$

$\begin{array}{ll}\text { Structural and Institutional Barriers } & 26\end{array}$

$\begin{array}{ll}\text { Academic barriers } & 26\end{array}$

$\begin{array}{ll}\text { Math anxiety } & 27\end{array}$

$\begin{array}{ll}\text { Workplace barriers } & 27\end{array}$

$\begin{array}{ll}\text { Few female peers and supervisors } & 27\end{array}$

$\begin{array}{lr}\text { Sexual harassment } & 28\end{array}$

$\begin{array}{ll}\text { Barriers Experienced Over Time } & 28\end{array}$

Integration of STEM Career Predictors $\quad 29$

$\begin{array}{ll}\text { The Current Study } & 34\end{array}$

Hypotheses 36

Proposed models $\quad 36$

Women 36

$\begin{array}{ll}\text { Men } & 36\end{array}$

CHAPTER II: METHOD $\quad 39$

$\begin{array}{lr}\text { Participants } & 39\end{array}$ 
Early Childhood Science Experiences Questionnaire

Family Involvement Questionnaire

Epistemic Curiosity Scale

Persistence Questionnaire

Influence of Role Models Scale

Math Self-Efficacy Scale

STEM Training Questionnaire

Inquiry Experiences in Science Classrooms Questionnaire

Demographics Questionnaire

Procedure

Ethical Considerations

Descriptive Statistics

Model Testing

Mixed-Methods Analysis of Barriers

General Discussion

Parental Educational Involvement

$\begin{array}{lr}\text { Parent Involvement and Persistence } & 68\end{array}$

$\begin{array}{lr}\text { Parents Fostering Curiosity } & 69\end{array}$

$\begin{array}{ll}\text { Childhood Informal Science Learning Experiences } & 70\end{array}$

Importance of STEM Self-Efficacy 
$\begin{array}{ll}\text { Teacher Influence on Self-efficacy } & 72\end{array}$

$\begin{array}{ll}\text { Classroom Inquiry Learning Experiences } & 73\end{array}$

$\begin{array}{ll}\text { Inquiry and Curiosity } & 73\end{array}$

$\begin{array}{ll}\text { Inquiry and Persistence } & 74\end{array}$

$\begin{array}{ll}\text { Inquiry and Self-efficacy } & 75\end{array}$

$\begin{array}{ll}\text { Barriers Experienced by Women } & 75\end{array}$

$\begin{array}{ll}\text { Limitations and Future Directions } & 76\end{array}$

$\begin{array}{ll}\text { Exploratory Analyses } & 76\end{array}$

$\begin{array}{ll}\text { Retrospective Report } & 77\end{array}$

$\begin{array}{ll}\text { Sample } & 77\end{array}$

$\begin{array}{ll}\text { Measuring STEM Self-efficacy } & 78\end{array}$

$\begin{array}{ll}\text { Mixed-methods Analysis } & 78\end{array}$

$\begin{array}{ll}\text { Reliability of Persistence Measure } & 78\end{array}$

$\begin{array}{ll}\text { Strengths of the Current Study } & 79\end{array}$

$\begin{array}{ll}\text { Sample } & 79\end{array}$

$\begin{array}{ll}\text { Measurement Improvements } & 79\end{array}$

$\begin{array}{ll}\text { Measuring STEM career aspirations } & 79\end{array}$

$\begin{array}{lr}\text { Measuring persistence } & 80\end{array}$

$\begin{array}{lr}\text { Measuring STEM self-efficacy } & 80\end{array}$

$\begin{array}{ll}\text { Predicted Models Informed by Data } & 81\end{array}$

Addition of Inquiry-based Learning Experiences $\quad 81$

$\begin{array}{ll}\text { Conclusions } & 82\end{array}$ 
$\begin{array}{lr}\text { REFERENCES } & 84\end{array}$

$\begin{array}{ll}\text { APPENDIX A: TABLES } & 100\end{array}$

APPENDIX B: CHILDHOOD SCIENCE EXPERIENCES QUESTIONNAIRE 106

APPENDIX C: MODIFIED VERSION OF THE FAMILY INVOLVEMENT

$\begin{array}{ll}\text { QUESTIONNAIRE - SHORT FORM } & 107\end{array}$

APPENDIX D: EPISTEMIC CURIOSITY SCALE 110

APPENDIX E: MODIFIED VERSION OF THE PERSISTENCE SCALE FOR

CHILDREN

APPENDIX F: MODIFIED VERSION OF THE INFLUENCE OF ROLE-

MODELS SCALE

APPENDIX G: MODIFIED VERSION OF THE MATHEMATICS SELF-

EFFICACY QUESTIONNAIRE

114

APPENDIX H: STEM QUESTIONNAIRE

APPENDIX I: INQUIRY EXPERIENCES IN SCIENCE CLASSROOMS

$\begin{array}{ll}\text { QUESTIONNAIRE } & 118\end{array}$

APPENDIX J: DEMOGRAPHICS QUESTIONNAIRE 120

APPENDIX K: A PRIORI CODING CATEGORIES FOR QUALITATIVE

ANALYSIS OF OPEN-ENDED QUESTIONS ABOUT CAREER BARRIERS 121

APPENDIX L: FINAL CODING SCHEME

122 


\section{FIGURES}

$\begin{array}{lll}\text { Figure } & \text { Page }\end{array}$

1. Christie's (2017) hypothesized model for factors influencing STEM career aspirations for women

2. Christie's (2017) hypothesized model for factors influencing STEM career aspirations for men

3. Christie's (2017) finalized accepted model for women

4. Christie's (2017) finalized accepted model for men

5. Proposed model for women

6. Proposed model for men

7. Results of original proposed model for men (top panel) and women (bottom panel) of the influences of parental educational involvement, informal science learning experiences, teacher influence, STEM self-efficacy, persistence, and curiosity on STEM career aspirations.

8. Finalized acceptable model for men (top panel) and women (bottom panel) 56

9. Results of original proposed models for men and women including IBL 


\section{CHAPTER I: INTRODUCTION}

In recent years, increasing attention among educational professionals and researchers has been given to fostering interest in science, technology, engineering, and math (STEM) among children and adolescents (NRC, 2010, 2012). As numerous studies have demonstrated, interest in science, self-efficacy for science, and positive attitudes about the importance of science to society predict aspirations to pursue a career in science, technology, engineering, and math fields (Lent, 1984; NRC, 2009). The significance of young people pursuing such careers remains an important topic of interest because, as many international studies have indicated, interest, selfefficacy, and positive attitudes toward science have significantly decreased in the United States and other western nations over recent decades (Department for Education, 1994; PCAST, 2010; Xie \& Archen, 2009).

Furthermore, this decline in interest, as well as the decline in favorable attitudes toward science, is an important area of inquiry because global society as well as the global economy continues to become increasingly dependent on science and technology for maintenance of lifestyles, access to vital resources, and jobs (Duschl, Schweingruber, \& Shouse, 2007). Because western society has become so reliant on science, engineering, and technology, it is important for educators to encourage students to take interest in and have positive attitudes towards the sciences, so that they will become adults who are scientifically literate and capable of both appreciating and evaluating science as it applies to their everyday lives. Declining interest in science and decreases in young people's aspirations to pursue science careers also remains a crucial area of concern because projected demand for individuals in science careers exceeds projections of individuals who are actually pursuing these careers (Mitchell \& Hoff, 2006; Riegle-Crumb, Moore, \& Ramos-Wada, 2011). Because of these concerns, increasing interest in 
science and aspirations to pursue science careers have also become a key focus of the National Research Council (NRC) and the President's Committee of Advisors on Science and Technology (PCAST), as indicated by their recently released reports (NRC, 2010).

The importance of public attitudes and interest in science can be illustrated by considering a topic such as the environment and global climate change. Recent research has indicated that despite increased attention to environmental problems in the beginning of the $21^{\text {st }}$ century, the public's investment in environmental issues has begun to decline. McCallum and Bury (2013) found through an analysis of Internet searches that inquiries about many issues such as conservation, biodiversity, fragmentation, and species extinction have been significantly declining in recent years. Because air and water pollution and global climate change remain threats to the environment (Field, Barros, Mach, \& Mastrandrea, 2014), the need for environmental science professionals to address these problems still remains. Furthermore, because the general population contributes to environmental problems such as pollution and resource depletion, it is important for the populace to be aware of and sensitive to their own role in environmental issues. Additionally, as Nisbet and Meyers (2007) examined in their research, public interest in climate change and other issues is strongly related to public policy about these issues. Particularly, Nisbet and Meyers (2007) found that public interest in environmental issues over the course of 20 years tended only to increase once environmental issues were already problematic. Thus, increasing environmental problems such as climate change illustrate the negative effects that can occur when the general public is scientifically illiterate or not interested in science topics. It is important, then, that all people remain interested in environmental concerns, not only those going into careers in these fields. 


\section{Science Interest and Gender}

There is evidence that interest in science is declining among all young people, but numerous research studies support the idea that despite efforts to bolster girls' interest and opportunities to pursue science careers, female representation in many areas of STEM careers still remains relatively low when compared to their male peers (e.g., National Science Foundation, 2009; Planty, Kena, \& Hannes, 2009; Cheryan, Ziegler, Montoya, \& Jiang, 2017). In the $20^{\text {th }}$ century, there existed a gap not only in interest but also in achievement between girls' and boys' performance in math. In recent years, however, this gap has begun to close (Hyde et al., 2008). Despite similar achievement in math and science, middle and high-school-aged girls' interest in science and math is still significantly lower than boys' interest in these subjects (Jacobs, 2005; Preckel et al., 2008). Researchers have proposed a variety of theories to explain why male and female students have differing interests in, attitudes towards, and opinions about science. Hypotheses have ranged from biological differences to the influence of the school environment to societal gender stereotypes about science illustrated in the media. Regardless of the explanation, there is evidence to suggest that discrepancy in science interest begins at a young age and that societal and educational factors have a great deal of influence, as addressed below.

\section{Parental Influence on Gendered Science Interest}

An area of research related to children's interest in STEM that has received a great deal of attention in past decades has been examining the role that parents play in influencing their children's perceptions of gender roles related to science. Many studies have identified that, beginning in infancy, parents behave differently towards their children depending on their child's gender (Bem, 1981; Lindsey \& Mize, 2001; Markus \& Oyserman, 1989). These parental 
behaviors and differences in gender socialization continue into the elementary school years, where parents have been found to be particularly influential in shaping their children's attitudes about academic subjects (Yee \& Eccles, 1998), especially attitudes about math (Ryan \& Patrick, 2001). Eccles (1990) also found that parents of male children believed that their children had higher levels of competence in math, and believed that lower levels of hard work would be required for success in mathematics than parents of female children did. Additionally, both parents of boys and girls in Eccles' (1990) study, regardless of the gender of their children, tended to believed that math was more important for boys than for girls.

Possibly the most important effect of parental math and science attitudes is that they have the potential to influence not only their children's attitude toward these subjects but also their performance in these areas. Notably, Jacobs (1991) found that parents' views about math strongly predicted their children's views of their own math abilities, even more than the children's own previous performance in math. In other words, girls whose parents believed their daughters to be less competent in math also had lower self-efficacy related to math ability, even when their grades and performance suggested otherwise. Furthermore, Jacobs found evidence that these students' self-perceptions regarding math also predicted their future math achievement. Some researchers have questioned when these differences in attitudes towards math and performance in math begin. Ambady et al. (2001) found evidence that such gender-differentiated attitudes about math and science were already present among preschoolers and kindergarteners. Thus, the body of research in this area indicates that gender differences in math and science attitudes, beliefs, and self-efficacy emerge at a very early age and are certainly influenced by parental attitudes and beliefs regarding these subjects. 


\section{Informal Science Experiences}

Another important area of study for gender differences in STEM interest in recent years has been in the area of informal science learning. Before many children are exposed to their first formal science classes in schools, they have opportunities to engage in informal science experiences, including television, Internet sites, libraries, and museums. Until recently, however, little research has examined how the experiences of girls and boys in these settings may differ. A common setting in which familial interactions with regards to informal STEM learning have been studied in recent years is museums.

To examine learning experiences among children in this setting, Crowley, Callanan, Tenenbaum, and Allen (2001) videotaped and analyzed the conversations of children and their mothers while they interacted with an exhibit in a children's museum. Coding of videotapes revealed that boys and girls showed no differences in their initiation of engaging with the exhibit, physically interacting with the materials in the exhibit, or the amount of time in which they stayed at the exhibit. In their analysis of conversations, however, researchers found that boys were more than three times more likely to hear explanations about the exhibits from their parents than girls were. Researchers initially hypothesized that parents explained more to boys because boys were asking more questions. Further analyses of the conversations revealed, however, that questions were rarely the antecedent to explanations by parents and that frequency of questions was not higher among boys than girls. Consistent with research discussed previously, this study also found that parents were more likely to explain to boys across all age groups, even as young as 1-3 years old. This indicates that gendered differences in informal science experiences, particularly in museum settings, begin at a very young age. Furthermore, because previous literature indicates that explanation such as causal statements can bring about better 
understanding and comprehension of scientific topics as well as interpretation of evidence and transfer of knowledge to new settings (Chi et al., 1994), girls may be at a distinct disadvantage for learning during informal science experiences compared to their male peers. Additionally, because favorable informal science experiences in childhood predict later positive attitudes toward and interest in science (Johnson, 1987; Kahle \& Lakes, 1983), it is possible that different experiences in science museums for girls may also explain a decreased interest in STEM later in life.

\section{Predictors of STEM Career Aspirations}

\section{Parental Influence}

Though there are a variety of factors that predict a child's interest in science, parent and caregiver influence has been shown to be one of the strongest of these influences (Gunderson, Ramirez, Levine, \& Beilock, 2012; Tiedemann, 2000). Parental school involvement is a multifaceted construct that includes a wide variety of parent behaviors and practices related to their child's education (Hill \& Taylor, 2004). Measures of parental involvement include assessing parents' communication with teachers, physical presence in the school building, parental expectations for achievement, and assistance and engagement with students' work outside of school (Funkhouser \& Gonzales, 1997).

As studies have indicated that parents play an important role in moderating academic achievement (Grolnick \& Slowiaczek, 1994), other researchers have looked toward the role parents might play in facilitating interest in school, including interest in academic subjects such as science and math specifically. There is evidence that parents play a critical role in fostering conditions that lead to school success for students of all ages (Henderson, 1987). Furthermore, there is evidence that when parents are not engaged in education, student achievement and 
outcomes worsen (Barnard, 2004). Thus, a great deal of research has focused on analyzing the role that parents play in children's academic achievement across school subjects. Fan and Chen (2001) found in a meta-analysis of 25 empirically based studies of parent involvement that parental involvement was positively correlated with student academic achievement. This pattern was true for children across age, gender, and race/ethnicity. Furthermore, the same results were found regardless of the type of measurement of subject area of academic achievement being measured (e.g., school grade point average, standardized test scores).

\section{Childhood Experiences}

A great deal of literature examines formal science education and informal science experiences that children are exposed to across development (Becker \& Kyungsuk, 2011). Various researchers have proposed that these experiences have potential to influence children's interest in science as a larger construct. George and Kaplan (1997) used data from the National Educational Longitudinal Study of 1988 to determine which variables of students' formal and informal science experiences were associated with their interest in science. Their sample included data from 7,980 eighth-grade students and their parents and teachers. The researchers used structural equation modeling to map the presumed causes and effects of various aspects of these students' circumstances to explain their overall interest in science. Parent involvement in both formal and informal science education was an extremely strong influence on children's attitudes toward science. Furthermore, George and Kaplan discovered that parental involvement was higher when parents had more education and more home resources. All of these variables then contributed to increasing frequency of science activities and visits to museums and libraries, both of which were associated with a greater interest in science. Other literature has focused specifically on what aspects of museum experiences may bolster skills related to science. 
Researchers have found that, in particular, talking and family conversations are mechanisms that support science learning (Crowley, Callanan, Jipson, et al., 2001; Haden, 2010).

Some studies have suggested that museum experiences also contribute not only to children's interest in science but also to their competency in science and related subjects. Haden et al. (2014) found, in particular, that children who received explicit instruction or information about STEM in a children's museum were more likely to recall information about STEM. In their study, children and parents participated in a building activity at one of the museum's exhibits. Children who received STEM instruction prior to the building activity were more likely to include more information about science, technology, engineering, and math when verbally describing their museum experience than children who received no such instruction prior to the building task.

Despite the strength of evidence demonstrating that family participation in science learning and informal science experiences predict science interest, one of the major critiques of models that propose to focus on these experiences is that all children do not have equal access to these types of activities (Bell, Lewenstein, Shouse, \& Feder, 2009). For example, Haden (2014) found that families who talk more to their children about science in museums are more likely to be European-American or White families than African-American or Hispanic/Latino families. Additionally, because one of the largest barriers to museum attendance is entrance fees (Kirchberg, 1998), children who are from higher socioeconomic status (SES) backgrounds may be more likely than children from lower SES families to be exposed to science museums and other informal learning settings across childhood and adolescence. Therefore, as interventions for expanding interest in science are considered, researchers must examine other predictors of a diversity of young people's aspirations to work in STEM fields. 


\section{Teacher and School Influence}

Another important influence on the development of positive attitudes toward science and further interest in science is formal education. Because of declining achievement in science in recent years (OECD, 2014), a great deal of emphasis has been placed on examining the educational variables that foster interest in science and promote academic achievement in science in schools as well.

Teacher relationships and support. Aside from parents, teachers are important adults in students' lives who play a role in shaping attitudes toward science. Regardless of grade level, effective instruction in science heavily depends on teachers. Teachers are essential for promoting students' curiosity, persistence, and interest in class material by directing attention, structuring lessons, and regulating the complexity of the information that is taught to them (NRC, 2007). In addition to their influence in promoting interest in science, teachers' support can also play an important role in shaping students' career decisions and vocational outcome expectations (Metheny, McWhirter, \& O’Neil, 2008).

One factor related to teacher influence is that positive educational achievement outcomes for students can be predicted by teachers' certification, education, teaching experience, and attitudes toward teaching (Darling-Hammond \& Hudson, 1988). When examining science in particular, other researchers found that student outcomes were strongly predicted by frequency of teachers' own exposure to science courses (Druva \& Anderson, 1983). Furthermore, Wright and Hounshell (1981) found that across environments, teachers were the greatest influence in stimulating interest in science. Maple and Stage (1991) found similar results and also found that teacher or school influences were even more important from the perspective of female students and students from racial minority backgrounds. 
These researchers have indicated the importance teachers have in promoting science interest in elementary school, but Dick and Rallis (1991) found that teacher influences are particularly important for high school students when making career choices. Their study, which analyzed the importance of various factors for choosing careers in STEM, found that teachers are one of the most important influences on students' choices to enter STEM fields. Teachers were more important in influencing these decisions for girls than boys. Thus, in addition to influencing interest in science, teachers may also play an important role in promoting interest in STEM careers for adolescents and mediating the STEM gender gap.

Teaching methods. Another important way that teachers influence students' interest in STEM is through the instructional methods they use in science courses. Historically, two approaches have been used to teach science, especially with respect to science process or scientific investigation skills: direct instruction approaches and inquiry-based teaching methods (Bell, Smetana, \& Binns, 2005). In a direct instruction model of teaching, instructors give students directions, provide students with factual information, and dictate relevant information to the topics emphasized in science courses. In contrast, however, inquiry-based approaches involve teachers challenging students to learn by forming their own questions and hypotheses as well as engaging in experimentation in order to discover the answers to scientific questions (Abd-ElKhalick et al., 2004). This approach emphasizes engaging in scientific practices, problemsolving, and maintaining and fostering a sense of curiosity among students.

Although these pedagogical approaches are very different from each other, teachers' instructional methods often do not fall at one extreme or the other. Rather, teaching styles may be conceptualized on a continuum between direct methods and inquiry-based methods. Bell, Smetana, and Binns (2005) developed a rubric in which inquiry-based teaching methods can be 
evaluated using four levels of classification ranging from high levels of teacher guidance and answer provision (level 0) to open inquiry methods in which students form their own research questions, collect their own data, and answer their own research questions (level 3).

Guided inquiry-based methods have been found to be linked with students' engagement in science, students' active scientific thinking, and better understanding of data results in scientific studies (Minner, Levy, \& Century, 2010). Thus, the methods that teachers use in science courses directly impact not only students' learning, but also their interest in and engagement with science. It is likely then, that teaching methods may play a role in predicting students' future career interest in STEM fields.

\section{Individual Differences}

An area of the current literature that is still developing is an examination of the specific features and traits of children and adolescents who have interest in science and wish to pursue careers in STEM, as well as the traits of individuals who have successfully attained careers in such areas (Lounsbury, 2012). Other research has linked certain traits to intention to pursue various careers such as art or music (Marchant-Haycox \& Wilson, 1992; Shelton \& Harris, 1979), but a gap in research linking characteristics to intent to work in STEM fields exists in the current literature.

Although there is a great deal of research examining the role of personality traits in overall vocational choices (Holland, 1985), the body of literature examined in this area goes beyond the scope of the current study. There is, however, a small body of literature examining common traits and characteristics among adults working in science fields. One such study conducted by Lounsbury et al. (2012) measured scientists' and non-scientists' personality traits using the Personal Style Inventory (PSI), a personality measure comprising the Big Five 
(Agreeableness, Conscientiousness, Emotional Stability, Extraversion, and Openness) as well as narrow personality traits such as assertiveness and optimism. Researchers examined PSI results of 80,768 individuals, 2,015 of whom were physical scientists (most of the scientist group comprised of chemists and physicists). Scientists rated significantly higher than non-scientists on measures of Openness, defined as "receptivity/openness to change, innovation, novel experience, and new learning" (p. 50). Scientists scored significantly higher than non-scientists on measures of Intrinsic Motivation, defined as "a disposition to be motivated by intrinsic work factors, such as challenge, meaning, autonomy, variety, and significance" (p. 51).

Because these traits have been demonstrated as being common to many adults who have pursued careers in science, it is worth examining whether or not certain individual difference traits may be associated with higher interest and positive attitudes toward science in childhood and adolescence, as well as likelihood of intention to pursue and persist in STEM careers later in life.

\section{Persistence}

Research has shown that many students change their majors during college, which is especially true for individuals with STEM majors (Daempfle, 2003). Furthermore, research has indicated that women and minority students are more likely than their male and white peers to change their majors and drop STEM classes (National Science Board, 2007). In an attempt to analyze the factors that contribute to this problem as well as remediate this problem, Maltese and Tai (2010) have asserted that persistence plays an important role in determining whether or not individuals interested in STEM careers will continue their education in these areas and gain employment in these fields. In addition to research that has linked persistence in education related to STEM fields with favorable job outcomes in these fields, other studies have also 
examined the role of task persistence specifically. Furthermore, other studies have found that persistence is correlated with academic achievement. A study by Lent, Brown, and Larkin (1984) in which subjects participated in a career planning course on science and engineering fields and were later given scales measuring grades, persistence, and self-efficacy found positive correlations between self-efficacy and grades as well as persistence and high grades.

Research activities in many of the STEM disciplines involve a great deal of repetition, reevaluation, and trial and error. Persistence, therefore, may be an important characteristic of those engaged in scientific research and science vocations. Recent research, however, has not examined persistence as an individual difference that may contribute to interest in science among young people. Therefore, it is worth investigating if both task persistence and persistence as a general individual characteristic is correlated with other traits common to scientists, such as interests and attitudes towards science in general.

Persistence has been studied since the early twentieth century and has been defined in many ways. Whereas many researchers thought of persistence as a key component of motivation (Atkinson, 1957; Danner \& Lonky, 1981), others believed persistence was a trait that was more common to some individuals than others (Eysenck, 1953). Definitions of persistence have included task-oriented definitions as well as definitions that have interpreted persistence as an innate characteristic. Some of the most widely accepted definitions of persistence are "a goal directed action" (Hebb, 1989) and an objective feature of purposeful behavior (McDougall, 1908).

Two primary methods of measuring persistence have emerged over the past century. The most common involved putting individuals in situations in which they needed to persist to complete the task demanded of them. This procedure included both tests of physical endurance 
and nearly unsolvable intellectual tasks (Morgan \& Hall, 1926). In these cases, researchers measure the amount of time that participants spent engaged in the activities demanded of them. In recent years, however, a more common method of measuring persistence has been the use of self-report rating scales. One of the scales that is commonly used is the Persistent Disposition Questionnaire, developed by Mukherjee (1974), which examines achievement-oriented personality.

One of the limitations of persistence rating scales such as this, however, is that they have only been tested with adults and thus may not be reliable for use with children and adolescents. Lufi and Cohen (1987) developed the Persistence Scale for Children, a 40-item true/false questionnaire that was specifically tested for reliability and validity with children aged 7 to 13 . Up until this point in time, persistence in children had only been measured through direct observation of tasks, as in the first method of persistence measurement described above.

\section{Curiosity}

Curiosity is a construct that has been studied for centuries and has been defined and described in a variety of ways (Jirout \& Klahr, 2012). Though researchers agree that curiosity is an important part of cognitive development, its definition remains elusive and often debated. Common themes in definitions include curiosity being a desire or appetite for information or knowledge and being intrinsically motivated. Lowenstein (1994) suggested that curiosity is caused by an incongruity in what an individual perceives in his or her environment and what he or she understands about this environment. Some have asserted that curiosity is caused by a discomfort with the unknown in one's environment, which in turn motivates exploratory thoughts and behavior (Lowenstein 1994, Piaget, 1952). 
Historically, two methods have been used to measure curiosity. Like measures of persistence, measures of curiosity include questionnaires or self-reports as well as behavioral measures. A variety of self-report questionnaires that measure curiosity have been developed for adult populations (Day, 1971; Leherissey, 1971; Spielberger, 1983), and at least one self-report measure of curiosity exists for children (Harty \& Beall, 1984). Most questionnaires that measure children's curiosity, however, rely on teacher or parent reports. Some of these developed questionnaires, such as the State Epistemic Curiosity Scale (Leherissey, 1971) measure taskspecific curiosity and view curiosity only as a temporary state. Other scales acknowledge both of these curiosity states, such as the State-Trait Curiosity Inventory (Spielberger, 1983) that examines curiosity by measuring in-the-moment curiosity as well as curiosity as an inherent trait. These differences in measuring curiosity as either a state or trait are indicative of the complexities involved with conceptualizing curiosity and illustrate the differences in opinion among curiosity researchers regarding the definition of curiosity.

Because of such diverse definitions and theories of curiosity, Jirout and Klahr (2012) have argued that self-report methods of measuring curiosity may lack validity and are difficult for respondents to truly conceptualize. Furthermore, because there is no universal definition of curiosity that exists across measurement techniques, Jirout and Klahr have proposed that selfreport methods of assessing curiosity lack construct validity. Thus, in recent years, researchers have turned toward measuring curiosity behaviorally, by observing actual exploration and information seeking behaviors as a hypothesized manifestation of curiosity (Jirout \& Klahr, 2012). Observing these behaviors ranges from natural to controlled environments and can examine both prompted and spontaneous exploratory behavior. Because of this broad range of 
conditions in which curiosity can be measured, many methodologies for observational measures of curiosity have been developed.

One such measure, developed by Kreitler, Zigler, and Kreitler (1975) measured children's responses as they were presented with novel objects and asked to describe them. Responses were coded to include both number of things said and types of details such as structure or function of the objects. This measure was used to assess conceptual curiosity. Other researchers have used methods to examine curiosity by measuring spontaneous exploratory behaviors. Some of these studies presenting children with novel objects and examining whether or not and how long the child interacts with these objects (McReynolds, Acker, \& Pietila, 1961; Minuchin, 1971). The studies described above examined curiosity by measuring non-verbal behaviors, whereas Endsley, Hutcherson, Garner, and Martin (1979) measured verbal behavior by tallying the number of questions participants asked while interacting with novel objects. Endsley et al. found that the number of questions asked was positively correlated with nonverbal exploratory behaviors. Some studies also investigated child-parent interactions. Children whose mothers engaged in more exploratory behaviors, question answering, and curiosity orienting behaviors were more likely to ask more questions and engage in exploratory behaviors themselves (Endsley et al., 1979; Saxe \& Stollak, 1971).

\section{Math and Science Self-Efficacy}

Another important predictor of math and science achievement is self-efficacy. Bandura (1997) defines self-efficacy as “the belief in one's capability to organize and execute the courses of action required to produce given attainments" (p. 3). Self-efficacy refers to a person's perceived capability in a given area. Math and science self-efficacy, then, refers to one's beliefs about their own skills in mathematics and science. 
Self-efficacy has been found to be correlated with a variety of positive outcomes, such as career performance, goal setting and motivation, and positive emotions (Larson et al., 2014; Lent, Lopez, Sheu, \& Lopez, 2011). It has been hypothesized that students with high academicrelated self-efficacy are more willing to participate in school, put more effort into school assignments, and are more resilient to school-related barriers than students who have doubts about their own skills (Zimmerman, 2000). For these reasons, it is believed that self-efficacy plays an important role in children's and adolescents' school performance and other schoolrelated outcomes, and there exists a variety of research that has examined the role that academic self-efficacy plays in predicting academic achievement (Chemers, Hu, \& Garcia, 2001; Schunk $\&$ Pajares, 2005).

\section{Self-Efficacy and Academic Achievement}

General academic self-efficacy has been identified as a major predictor of student academic performance (Schunk \& Pajares, 2005). In other words, students who perform well in school tend to believe that that their own academic skills are high and they have high confidence in their ability to perform well in school. Thus, it is believed that higher academic achievement is associated with higher self-efficacy. Chemers, Hu, and Garcia (2001), however, examined the role that academic self-efficacy played in predicting college academic performance. They found that college students who had high academic self-efficacy were more likely to perform well during their first year of college than those who had low academic self-efficacy. Furthermore, there is evidence that in addition to predicting academic performance, self-efficacy predicts aspirations to pursue in a STEM profession (Marra, Rodgers, Shen, \& Bogue, 2009). 


\section{Teacher Support and Self-Efficacy}

According to Bandura (1997) role models play an important role in shaping self-efficacy through opportunities for vicarious learning. Bandura asserts that when one sees another person successfully completing a task, it increases the likelihood that he or she will feel more confident in completing the same task. For example, if a student watches another person solve a math problem, he or she may feel more confident in their own ability to solve a similar problem because they now have a better idea of how they might go about solving it.

Observational learning is another central component of Social Cognitive Career Theory (Lent, 1990). According to this model, role models serve as influential figures that influence young people's interest in and skills in certain career paths. Teachers in particular have been found to be especially important in serving as role models for young people in addition to playing an important role in teaching the skills necessary to be successful in future careers (NRC, 2007).

Furthermore, there has been research that has indicated that teachers play a direct role in influencing students' self-efficacy related to academics (Fast et al., 2010). Teachers specifically play an important role in fostering academic self-efficacy because they are responsible for structuring classroom climates. Fast et al. (2010) examined how classroom factors were related to self-efficacy, and found that perceiving one's teacher as caring was a significant predictor of academic self-efficacy. The results of Fast and colleagues' research suggest that specific teacher qualities and behaviors may foster self-efficacy for students. It is possible, then, that teacher support for students' favorite subjects or career goals may directly predict students' academic self-efficacy, although further research is needed to provide such evidence. One goal of the 
current research was to examine whether teacher support for career choice in a STEM field predicts self-efficacy for math and science.

\section{Gender Differences in Math and Science Self-Efficacy}

As previously discussed, in recent years, the math achievement of male and female students has begun to become more similar, despite boys performing at higher math levels in previous years (Jacobs, 2005; Preckel et al., 2008). In a 2008 study conducted by Hyde and colleagues, researchers found that boys and girls performed similarly in math, and that girls even outperformed boys in some areas when controlling for race. Interestingly, however, research indicates that despite equal achievement in math, girls' self-efficacy remains low compared to same grade-level male peers. Reis and Parks (2001) found that among a sample of high school students, boys had significantly higher self-efficacy than girls did on average. Wigfield et al. (1997) found similar results among elementary school students, indicating that gender differences in math self-efficacy begin at a young age. Additionally, Eccles et al. (2000) found that girls who have high performance in math, or are considered gifted, generally underestimate their own math abilities, but gifted male students more accurately estimate their own skills. This phenomenon is sometimes referred to as the "confidence gap." Goetz et al. (2013) found that in addition to math, girls had lower self-efficacy than boys with regards to STEM subjects in general.

These studies highlight the gender differences in math self-efficacy during childhood and adolescence. There is evidence, however, that gender differences in math self-efficacy persist into adulthood. Peters (2013) found that a sample of undergraduate students did not differ in math performance by gender in their undergraduate algebra classes. Despite no differences in performance, however, women reported significantly lower math self-efficacy than men. Riggs 
(1991) found evidence that lower science self-efficacy persists into adulthood and may later manifest as STEM career self-efficacy. Riggs found that among a sample of science teachers, men rated their science-teaching self-efficacy higher than female teachers did. Based on the existing literature, it appears that gender differences in math and science self-efficacy begin at a young age and persist into adulthood. Furthermore, as research has linked self-efficacy to performance in math and science, it seems likely that self-efficacy plays a role in decisions and motivations to pursue STEM careers.

\section{Self-Efficacy and Persistence}

It is possible that self-efficacy in math and science may play a role in predicting persistence in STEM careers. Bandura (1997) claimed that general self-efficacy with regards to a task would likely predict persistence in achieving that task. In other words, people who are confident in their own ability to complete a task are more likely to persevere in finishing that task those who do not believe they can complete it. Pajares (1996) also suggested that selfefficacy predicts both higher persistence in a given task and more resilience to barriers related to completing a given task.

In addition to STEM self-efficacy predicting persistence in academic tasks related to STEM, it is possible that one's beliefs about his or her own ability to successfully attain and do well in a STEM career may influence an individual's persistence to remain in STEM education and training. Simon et al. (2015) examined the specific role that self-efficacy plays in predicting persistence to stay in STEM careers. In this study, Simon and colleagues found that self-efficacy did predict persistence in STEM careers, as measured by students' enrollment in a STEM program and found that this relation was mediated by motivation, as measured by an academic motivation scale. Lee et al. (2015) found similar results that indicated among a group of students 
in an engineering program, self-efficacy predicted higher levels of career-related persistence. Thus, evidence exists supporting the role that self-efficacy plays in predicting STEM career aspirations and persistence.

\section{Gender-Related Barriers to STEM Career Attainment}

Although a variety of factors influence female students to gain interest in and later pursue STEM careers, there are also various barriers that may deter women from persisting in STEM career education and training. As previously stated, women are significantly less likely to choose STEM majors in college than men, and women who are enrolled in science majors are significantly more likely to drop or change their major to a non-STEM discipline (National Science Board, 2007). Many researchers have focused on the factors that serve as incentives or positive sources of motivation for women staying in STEM fields, such as parenting factors, education factors, and individual differences (Christie, 2017; George \& Kaplan, 1997; Gunderson, Ramirez, Levine, \& Beilock, 2012; NRC, 2007). Furthermore, in the past, researchers focused on internal deficits that might cause women to experience difficulty in STEM fields (Sadker \& Sadker, 1994). In recent years, however, an increasing body of research has examined contextual and environmental factors in STEM disciplines that may act as deterrents that decrease women's motivation to stay in a STEM profession.

\section{Social Barriers}

Many of the barriers that women pursuing STEM careers face are related to socialization and interaction with peers, colleagues, mentors, and superiors. A breadth of research has examined the way in which gender socialization, gender stereotypes, and microaggressions impact women's interest in and willingness to continue to pursue STEM (Grossman \& Porche, 
2014, Fritsch, 2015). Unfortunately, barriers to women's motivation for STEM begin at a young age and persist, or even worsen, into adulthood (Fouad et al., 2010).

Gender role socialization. From an early age, boys and girls are treated differently by parents and other adults based on their biological sex, and reinforced for specific behaviors that are considered associated with their ascribed gender (Bem, 1981). Gender socialization is particularly important with regards to reinforcing boys' and girls' interest in and performance in math and science. As previously stated, parents tend to believe math is more important for boys than girls, and children develop these views over time as well (Eccles, 1990; Jacobs, 1991). Attitudes and practices about the appropriateness of math and science for girls is also present at a societal level. For example, children's toys are often differentially marketed by gender. Specifically, toys marketed to boys are more likely to include aspects related to technology and engineering, such as items for building, science experiment toys, and toys involving use of mathematics (Bussey \& Bandura, 1999). The internalization of gender role socialization can be demonstrated with the classic stereotype threat manipulation. In a 2001 study, Quinn and Spencer induced stereotype threat about women's low math performance and ability in a laboratory settings and asked participants to complete a math assessment. They found that women who were exposed to gender stereotypes about math performed significantly lower on the math test than those not exposed to the stereotypes, thus highlighting how internalization of gender socialization directly affects academic performance. Other researchers have suggested that girls internalize the attitudes and implied messages about their ability to be successful in math and science, and these attitudes may decrease their interest and persistence to pursue a career in STEM (Shapiro \& Williams, 2011), though further research is needed in this area. 
Gender stereotypes. Another factor related to perception and treatment of women in the workplace is stereotypes that people hold related to gender. A variety of research has examined gender expectations and how these may affect outcomes for women in STEM fields.

Intelligence. A prevalent stereotype that affects perceptions about and treatment of women in a variety of academic and career settings is perceived intelligence of women. Prior to the twentieth century, some research in the field of biological sex differences involved examination of skull sizes as a predictor of brain size and intelligence (Sadker \& Sadker, 1994). For a time, it was believed that women were innately less intelligent than men because of a smaller average skull size (Hyde, 1996). Although this method was eventually discarded and replaced with more valid means of measuring the construct of intelligence, and findings indicate that intelligence is equivalent across gender on average (Flanagan, Genshaft, \& Harrison, 2012), attitudes about men being more intellectually competent than women still persist (Blickenstaff, 2005). In fact, the president of Harvard recently suggested that the relative scarcity of women in "high-end" science and engineering professions is attributable in large part to male-female differences in intrinsic aptitude (Summers, 2005).

Stereotypes about intelligence and how intellect influences academic skills and proficiency also affects how female students are perceived in terms of math and science skills. Research has indicated that parents generally tend to view male children as being better at math than female students (Eccles, 1990). Interestingly, children themselves seem to hold this viewpoint as well, as both girls and boys tend to rate boys' math skills as being higher than girls' math skills on average (Jacobs, 1991). As discussed previously, both low expectations from adults as well as low math and science self-efficacy likely influence girls' levels of interest in 
STEM, and in turn, influence the likelihood that they will later pursue and persist in STEM career fields.

Rationality and emotion. Another common stereotype about women is that they tend to be more emotional than men. Although women may be mislabeled as overly emotional or lacking rational tendencies in a variety of career and educational settings, Gilbert (2001) argues that the emotion-driven stereotype of women might be particularly damaging with regards to science. Gilbert argues that science is associated with being rational and logical -- qualities that are typically associated with masculinity. She argues that in general, scientists are trained to value logic over emotion and are expected to make decisions in this way as well. Blickenstaff (2005) asserts that this stereotype of women, then, may be primed in STEM work settings, and women in STEM fields thus may be treated poorly if they are perceived to be emotional.

Lack of female role models. Role models are important figures that serve as an example of competence and achievement that one can look to as a guide or example of behavior and expertise within a given area (Lockwood \& Kunda, 1997). Role models are particularly important for school and academic domains because positive relationships with and perceptions of role models are correlated with higher self-efficacy and higher academic performance (Marx \& Roman, 2002). Unfortunately, however, another barrier women experience from an early age is lack of female role models in math and science. As previously stated, there is a higher proportion of male math and science teachers, especially in the areas of engineering, physics, and chemistry (NSF, Division of Science Resource Statistics, 2004). College STEM-related departments (e.g., computer science, chemistry, physics) are also primarily comprised of male faculty members (NSF, Division of Science Resource Statistics, 2004). Furthermore, role models can serve as sources of advice and guidance about potential career paths and can aid in the career 
decision-making process. Therefore, it is possible that due to lower numbers of female role models, that women interested in STEM may receive less information about how to pursue a STEM career after completion of high school.

It has been suggested that the presence of female teachers serving as role models may directly increase women's self-efficacy and performance in STEM subjects. To test this hypothesis, Marx and Roman (2002) conducted an experimental study in which either a male or female examiner administered a math test to participants. To provide evidence of expertise in math, the male or female examiner explained that they had created the assessment being used, and would provide the participant with feedback. Female participants performed significantly better on the math test when a female examiner administered it and rated themselves as having higher self-efficacy with regards to the task. Furthermore, participants' perceptions of the examiner's mathematics competence predicted performance on the math exam. Thus, the results of this study indicate the importance of female STEM role models for both STEM performance as well as STEM self-efficacy.

Microaggressions. Another form of discrimination women may receive from adults or from peers are microaggressions with regards to STEM performance and capabilities. Sue and colleagues (2007) define microaggressions as "brief, everyday exchanges that send denigrating messages to people of color because they belong to a racial group" (p. 272). It is important to note that while this description of microaggressions applies to race, microaggressions can be committed on the basis of gender and other group memberships as well. Rather than being overt acts of discrimination, microaggressions are often subtle statements that occur in typical social interactions. Some microaggressions are intentional and meant to invalidate and demean others, but others are often unconscious and even unintended on the part of the aggressor. Despite 
intention, however, microaggressions have the effect of undermining those who are the target and serve to maintain stereotypical beliefs about people from certain groups. Furthermore, microaggressions have been shown to be associated with development of negative psychological outcomes (Huynh, 2012).

Although initial conceptualization of microaggressions involved race-related statements and behaviors, microaggressions can target gender as well. Gender-related microaggressions often reinforce assumptions of traditional gender roles (Grossman \& Porche, 2014). It has been proposed that gender-based microaggressions may be particularly harmful for female adolescents and young adults in the midst of career development and selection, especially for women in STEM fields due to underrepresentation. Grossman and Porche (2014) conducted a study in which they interviewed adolescents about microaggressions they experienced and observed, and found that over $66 \%$ of their sample observed microaggressions related to gender stereotypes of women with regards to female participation in STEM. Thus, there is evidence that microaggressions are a significant barrier that women experience in STEM training and professions.

\section{Structural and Institutional Barriers}

In addition to the barriers women face with regards to socialization related to gender and social interactions with peers and mentors, there are also barriers that exist within institutions related to STEM education and STEM vocations. Specifically, there are aspects of education and workplaces that present barriers to women's success.

Academic barriers. One setting that presents barriers to women's interest and achievement in STEM from a young age is schools. As previously outlined, there are a variety of school-related factors that negatively affect girls' interest in math and science, including more 
male than female teachers in STEM subjects and microaggressions related to women's intelligence and STEM skills. Furthermore, there is also evidence that teachers generally perceive boys to be "smarter" and more competent in math and science than girls, even when girls received the same grades and test scores ( $\mathrm{Li}, 1999)$.

Math anxiety. A topic that has received a great deal of attention from researchers in recent years is math anxiety. Math anxiety refers to the phenomenon of developing fear and worry about one's performance in mathematics activities or tests. Research has indicated that math anxiety seems to be a gendered experience, as results of studies examining math anxiety among elementary school and middle school students indicated that girls experience math anxiety more often than boys, and that girls have more intense anxious reactions to math than boys do (Wigfield \& Eccles, 1989; Wigfield \& Meece, 1988). Interestingly, Beilock et al. (2010) found that female teachers also experience math-related anxiety at higher levels than male teachers, and that female teachers who experienced math anxiety at high levels were more likely to cause female students in their courses to develop math anxiety by the end of the school year. Thus, there is evidence that schools and teachers can have direct negative effects on girls' selfefficacy and performance in mathematics.

Workplace barriers. In addition to the difficulties women experience in STEM classes during school years, there is evidence that discrimination and other barriers also exist in institutions of higher learning and in the workplace for women in STEM.

Few female peers and supervisors. As stated previously, most STEM professions are predominantly comprised of men. Another important effect of low female representation in these fields is that women in the STEM workforce have few female colleagues and supervisors. Research has indicated that in many universities, senior professors in a variety of departments, 
including STEM departments, are mostly men (Macfarlane, 2012). In a study examining the barriers women in academia perceived with regards to working in a male-dominated environment, Howe-Walsh and Turnbull (2016) found that women experienced intimidation from male superiors, harassment, and gendered statements from male colleagues. Furthermore, women in this study reported feeling uncomfortable with and having difficulty networking in STEM fields due to low female representation. Fritsch (2015) also found among a sample of female scientists in academia that many women reported difficulty in socializing at work and connecting with co-workers due to the workplace being a male-dominated space.

Sexual harassment. Another issue that women have cited as a barrier in STEM professions is overt sexual harassment from male colleagues and superiors. Sonnert and Holton (1995) found that among a sample of 191 female science fellowship recipients surveyed, 12\% had experienced sexual harassment. Although women experience sexual harassment in a variety of professions and not STEM alone, it is possible that experiencing sexual harassment may be more damaging in the context of fewer female peers in the workplace and poor perceived work climate.

\section{Barriers Experienced Over Time}

Unfortunately, there is evidence that suggests that many of the barriers discussed only intensify and increase over time. Fouad et al. (2010) examined perceptions of barriers in STEM fields across a sample comprised of middle school students, high school students, and college students, and found that as age increased, perceptions of number and intensity of barriers related to STEM career entry increased. Additionally, Brainard and Carlin (1998) examined perceived barriers among women in science majors in college in a longitudinal study and found that only 
$3 \%$ of freshman perceived significant barriers to their career. This number increased to $20 \%$, however, by the time they were seniors.

Based on the body of literature regarding barriers in STEM education and careers, it is clear that many women are faced with obstacles related to their gender from a young age. Although a great deal of research has examined the effects that these barriers have on women's self-efficacy, performance, and desire to enter into a STEM career, there is still research needed to examine how barriers may influence other motivational factors that lead women to STEM professions, including some of the factors examined in the current study.

\section{Integration of STEM Career Predictors}

To date, some studies have examined relations between some variables related to STEM career aspirations, such as teachers influencing science interest (Maple \& Stage, 1991) and parents influencing early STEM exposure and learning experiences (Haden, 2010). Few studies, however, have examined how multiple predictors of STEM career interest, including parent and teacher influence, STEM experiences, and individual differences relate to each other and develop over the course of childhood and adolescence. Furthermore, not many studies have examined gender differential pathways to STEM career aspirations using these variables. One study that did examine the interplay between multiple different predictors of career outcomes was conducted by Lent, Brown, and Hackett (1994). These researchers identified multiple different predictors and concluded that personal factors (e.g., gender), contextual factors (e.g., support systems), and experiential factors (e.g., learning) interact with self-efficacy and individual goals

and interest to predict one's career outcomes and attainment. Lent and colleagues referred to the interaction of these systems as "Social Cognitive Career Theory." Specifically, Lent and colleagues found that these personal, contextual, experiential factors served as "sources" of 
expectations and self-efficacy, and that higher levels of self-efficacy then predicted higher levels of interest in a given field.

Christie (2017) expanded on this theory, examining personal, contextual, and experiential factors by specifically analyzing the relations between parental education involvement, early informal STEM learning experiences, individual differences in persistence and curiosity, teacher support for career choice, and STEM career aspirations. Path analysis was used to examine pathways to examine how these variables influenced college students' choices to pursue a career in science, mathematics, engineering, or technology. Because of the different experiences boys and girls are exposed to from a young age regarding STEM, this study used two hypothesized models - one for women (see Figure 1) and one for men (see Figure 2).

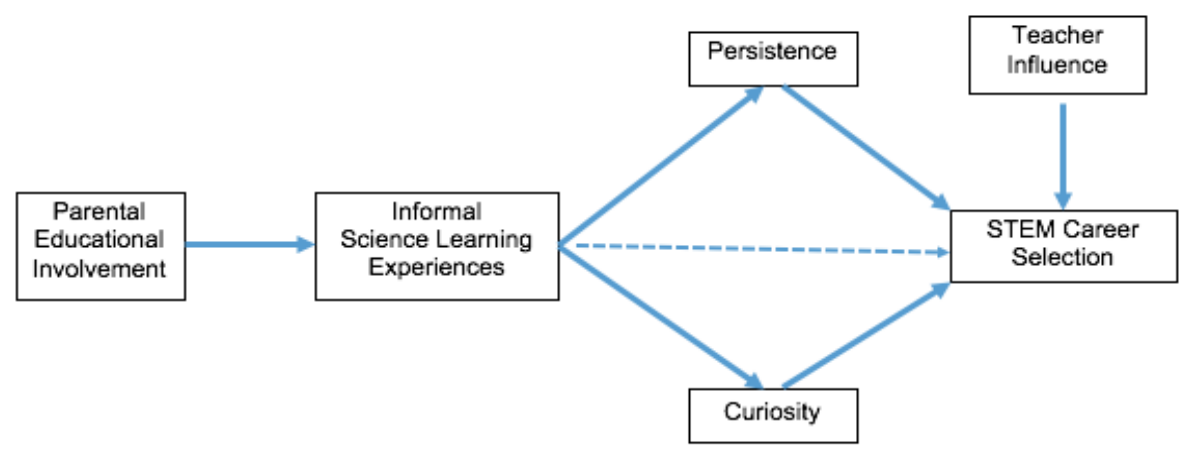

Figure 1. Christie's (2017) hypothesized model for factors influencing STEM career aspirations for women.

For women, it was hypothesized based on the literature that parents who were highly involved in their child's education would be more likely to attend informal science learning settings (e.g., children's museums, zoos, aquariums) with their children. It was then hypothesized that because of more exposure to these types of STEM experiences, children would report higher 
levels of curiosity as well as higher levels of persistence. High self-ratings of persistence and curiosity were hypothesized to be predictive of STEM career aspirations, as curiosity is important for novel-seeking and experimentation, an important aspect of STEM careers, and persistence is important for women to overcome barriers to pursuing a STEM career. Based on the literature examining the relation between teacher support and career decision-making, it was hypothesized that participants whose teachers were more supportive for their career choice would be more likely to pursue a career in STEM.

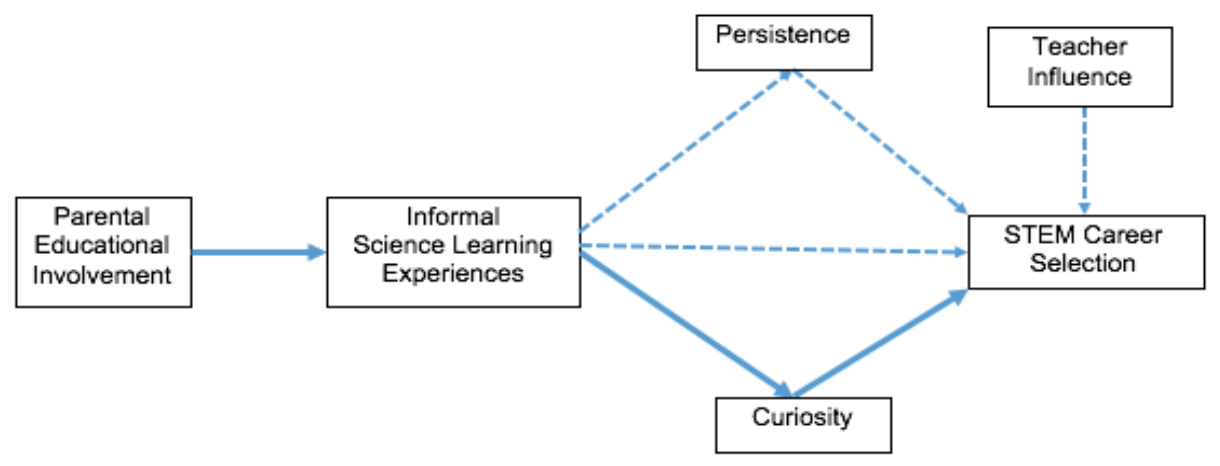

Figure 2. Christie's (2017) hypothesized model for factors influencing STEM career aspirations for men.

For men, it was also hypothesized that children whose parents were highly involved in their education would be more likely to be involved in informal science learning and because of more exposure to these types of STEM experiences, male participants would report higher levels of curiosity. For men, it was hypothesized that the relation between early STEM experiences and persistence, as well as the relation between persistence and STEM career aspirations would be weak because persistence is not as important for men, as they face fewer barriers while pursuing 
a career in STEM than women do. It was hypothesized, however, that curiosity would be predictive of STEM career aspirations, as this remains an important individual difference that may play a role in STEM career interest and success. Additionally, it was hypothesized that the relation between teacher career support and STEM career aspirations would be weak for men, as men have same-gender role models in STEM aside from their teachers, unlike women.

Although collected data supported some of the predicted relations in this model, support was not found for all hypothesized relations within each model. However, exploratory analyses were conducted, and models that fit the collected data for women (see Figure 3) and men (see Figure 4) were constructed.

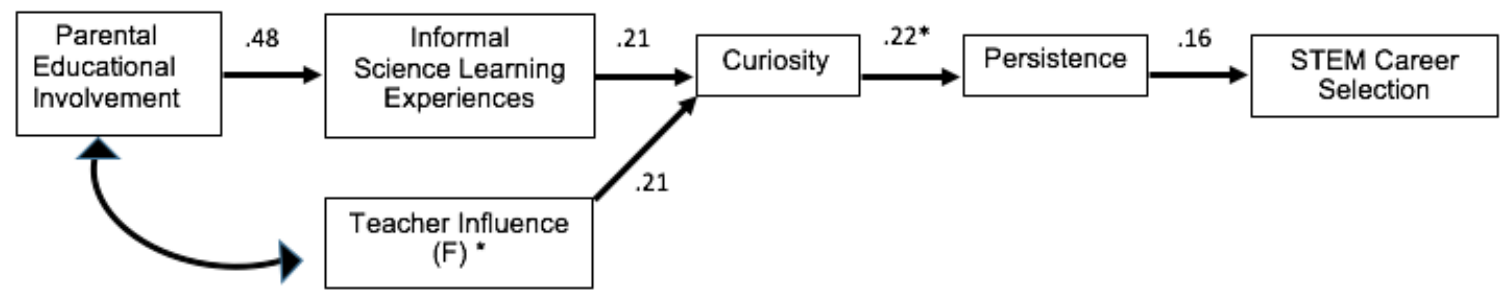

Figure 3. Christie's (2017) finalized accepted model for women.

Christie (2017) found, consistent with hypotheses, that for women, children whose parents were highly involved in their education were more likely to engage in informal science learning experiences throughout early childhood. Additionally, there was support for the hypothesis that these experiences would foster higher levels of curiosity among children who attended informal STEM learning experiences more frequently. There was also support for the hypothesis that higher levels of persistence would predict aspirations to pursue a career in STEM. However, it was found that early informal STEM learning experiences were not a 
predictor of higher levels of persistence. Interestingly, however, it was found that higher levels of curiosity predicted higher levels of persistence women. Although no studies have examined the relation between curiosity and persistence to date, it is very possible that high motivation to learn more about a given topic (curiosity) may directly relate to how much one will persevere in attempting to seek information. Christie also found that teacher support was not a significant predictor of STEM career aspirations, but rather, that teacher support was a predictor of curiosity. Christie discussed this effect by suggesting that teachers are primarily responsible for introducing children to various academic topics, and thus, teachers (especially highly supportive teachers) may be responsible for fostering a sense of curiosity about various subject among children. Although no studies have directly examined the relation between teacher support and curiosity, teacher support has been linked to student engagement (Klem \& Connell, 2004). It is also possible that teachers' pedagogies may also influence curiosity.

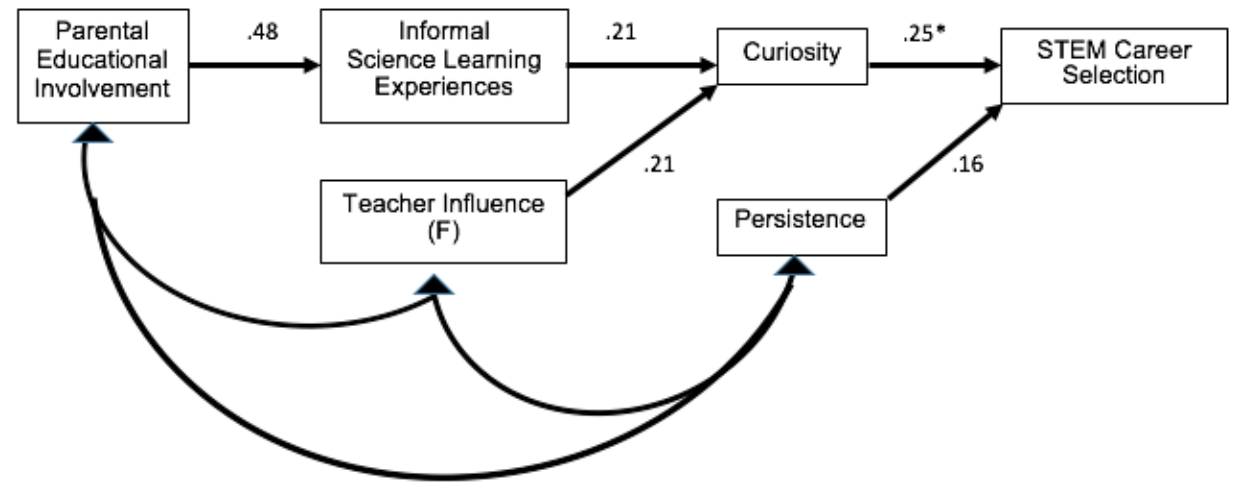

Figure 4. Christie's (2017) finalized accepted model for men.

Many of the same relations were found for men in this study. Specifically, it was found that for men, children whose parents were highly involved in their education were more likely to engage in informal science learning experiences throughout early childhood. Like in the model 
for women, there was support for the hypothesis that these experiences would foster higher levels of curiosity among children who attended informal STEM learning experiences more frequently. There was support for the hypothesis that higher levels of persistence would predict aspirations to pursue a career in STEM. However, early informal STEM learning experiences were not a predictor of higher levels of persistence for men.

In the model for women, it was discovered that curiosity predicted persistence, but this pattern was not found for men. Christie suggested that for both men and women, it was possible that persistence is more of a dispositional trait and may not be able to be predicted by experiential factors (i.e., informal STEM learning experiences). Although a link may exist between these experiences and persistence, it is possible that this relation is mediated by other variables, including interest, self-efficacy, or how often individuals encounter barriers. Consistent with the model for women, teacher support was not a significant predictor of STEM career aspirations, but rather, teacher support was a predictor of curiosity.

Because these models were the result of exploratory analyses, additional data were needed to test these models, which the current study attempted to do. The final models from Christie (2017) were examined in the current study, but with the addition of self-efficacy.

\section{The Current Study}

In recent years, research has demonstrated that positive public attitudes toward science have been decreasing (PCAST, 2010; Xie \& Archen 2009). Additionally, students' performance in math and science in the United States has also been low compared to students in other developed nations (OECD, 2014). Furthermore, there is a need for professionals in STEM careers, as projected needs are higher than the number of people entering these fields (PCAST, 
2010). An especially concerning problem within STEM is the underrepresentation of women in positions in these career fields (NCES, 2001; NSF, 2009).

In an attempt to increase both interest and performance in science and math among children, and increase interest and persistence in STEM careers among young adults, a great deal of research in recent years has focused on the factors that increase young people's interest in science and math, increase academic performance in these subjects, increase interest in careers involving training in STEM, and improve positive attitudes about science throughout society. Specifically, much of this research has examined the role that parenting practices and early exposure to STEM learning experiences play in predicting later interest in STEM subjects and school and later interest in STEM careers. Other studies have focused on the role that formal educational experiences play, such as the role of school environments and the influence that teachers have in bolstering STEM interest, providing guidance about STEM career opportunities, and serving as STEM career role models. Other research, however, has examined the role that self-efficacy in math and science plays in predicting aspirations to choose college majors in STEM disciplines and persist in these fields into adulthood. Furthermore, some researchers have focused on how individual differences that may be compatible with the demands of STEM careers may help individuals succeed in these fields (Bachtold \& Werner, 1972; Feist, 1998). Furthermore, many studies have specifically examined the barriers than women face at various ages and in various environments while attempting to pursue careers in STEM.

Although many studies have examined effects that various predictors of STEM careers have independently on predicting STEM career aspirations, fewer studies have examined the effect that these predictors have sequentially as these experiences and factors interact throughout development. Acknowledging the importance of early childhood experiences, parental 
educational involvement, and teacher support, in the current study, I examined the effect that these factors have in shaping later math and science self-efficacy and partially predicting individual differences such as persistence and curiosity. Furthermore, the current study examined the role that each of these factors has in influencing choice to enter a STEM career, and I examined how the relations between these variables as they effect STEM career entry differ for men and women. Finally, the current study examined the barriers that young people experience in their intended or current careers in order to identify specific barriers to pursuing a STEM career. In particular, the current study focused on the barriers that women in STEM fields (or those who have chosen an alternative to a STEM career) experience.

\section{Hypotheses}

Proposed models. First, I hypothesized that students' aspirations to pursue or involvement in STEM careers would be predicted by parental involvement in childhood education, informal childhood science learning experiences, teacher support for career choice, math and science self-efficacy, and individual differences in persistence and curiosity. Specifically, however, I proposed differentiated models in which the relations between these variables varied according to gender.

Women. For women, I proposed a model in which parental involvement in childhood education would lead directly to informal science learning experiences. I hypothesized that higher frequency of informal STEM learning experiences would be predictive of higher levels of curiosity. I also hypothesized that math teacher and science teacher support for career choice would be predictive of higher levels of curiosity as well as higher levels of math and science self-efficacy. I hypothesized that higher levels of curiosity and higher levels of math and science self-efficacy would predict higher levels of persistence. Finally, I hypothesized that higher levels 
of persistence would be predictive of aspirations to pursue careers in STEM. Figure 5 represents the overarching hypothesized model for women's aspirations to pursue science careers, in which parental involvement predicts informal science learning experiences, and informal science learning experiences predict curiosity, and teacher influence predicts both curiosity and math and science self-efficacy. Curiosity and math and science self-efficacy both predict persistence, and persistence was hypothesized to predict STEM career aspirations. The only way in which this proposed model differs from Christie's (2017) model is the addition of the variable of math/science self-efficacy (with teacher influence predicting self-efficacy and self-efficacy predicting persistence).

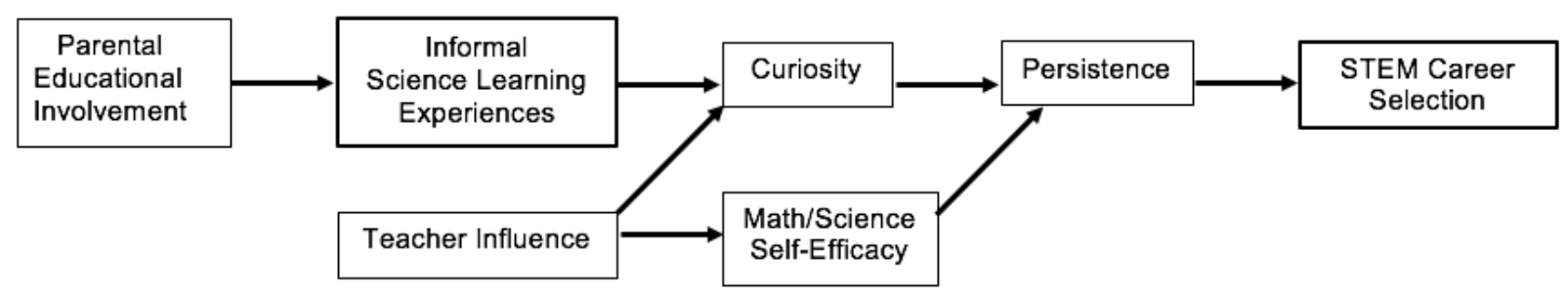

Figure 5. Proposed model of the influences of parental educational involvement, informal science learning experiences, teacher influence, math and science self-efficacy, persistence, and curiosity on STEM career aspirations for women.

Men. For men, I also proposed a model in which parental educational involvement would directly lead to more frequent experience of informal science learning opportunities. I then hypothesized that higher levels of STEM informal learning experiences would be predictive of higher levels of curiosity. I hypothesized that support from math and science teachers would also be predictive of higher levels of curiosity as well as higher levels of self-efficacy in the areas of math and science. I hypothesize that math and science self-efficacy would be predictive of higher 
levels of persistence, and that higher levels of both persistence and curiosity would directly predict aspirations to pursue a career in STEM. Figure 6 outlines the hypothesized model for men's entry into STEM careers, in which parental educational involvement predicts informal science learning experiences, which in turn predict STEM career aspirations, with informal science learning experiences predicting curiosity and curiosity predicting STEM career aspirations. For men, it was hypothesized that math and science teacher influence would predict both curiosity and math/science self-efficacy, that math/science self-efficacy would predict persistence, and both curiosity and persistence would predict STEM career aspirations. One of the key differences between the proposed models for women and men is that curiosity and persistence are parallel predictors for men, but serial predictors for women. In other words, high levels of curiosity are predicted to be necessary but not sufficient for women in the absence of high levels of persistence as well.

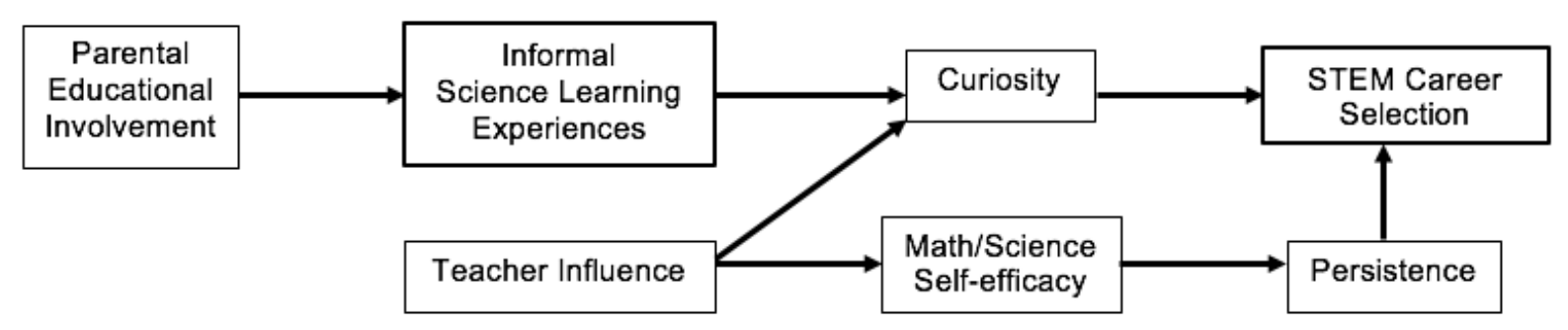

Figure 6. Proposed model of the influences of parental educational involvement, informal science learning experiences, teacher influence, math and science self-efficacy, persistence, and curiosity on STEM career aspirations for men. 


\section{CHAPTER II: METHOD}

\section{Participants}

For the current study, graduate and undergraduate students were recruited both from a large public university in the midwestern United States and from other universities using socialmedia recruitment. Students recruited at the midwestern university were recruited using the university Psychology Department's participant pool. I also made announcements in classes containing large numbers of students and handed out flyers with information about the study and the survey website to students in these courses. All participants who completed the online survey had the option of being entered into a random drawing to potentially receive a gift card.

The degree of completion of the online survey varied. All participants who failed to complete any one full measure of the questionnaire $(N=146)$ were removed to clean the data. The result of this process yielded data from 467 participants: 190 male and 277 female students. Of these participants, $28.7 \%$ were freshmen in college, $20.3 \%$ were sophomores; $21.4 \%$ were juniors, $16.0 \%$ were seniors, and $13.3 \%$ were continuing education or graduate students. With respect to race/ethnicity, $72.9 \%$ of participants were white/European-American; $5.7 \%$ were Black/African-American; 6.0\% were Asian/Pacific Islander; 8.0\% were Hispanic/Latino; 5.7\% were biracial or multiple races; and $1.2 \%$ of participants identified as "other." The participants were students from a wide variety of academic majors including physical science majors (e.g., chemistry, physics), humanities majors (e.g., English, history, art), and social science majors (e.g., psychology, sociology; see table 5). Non-stem majors were recruited to gain more variability in responses on the STEM career aspirations outcome measure 


\section{Measures}

Early childhood science experiences questionnaire. To assess the types of childhood experiences to which participants were exposed and how often they had exposure to these experiences, a 10-item measure of extracurricular and community-related experiences related to science was developed by Christie (2017) and was used in the current study (see Appendix A). Each item in the questionnaire can be responded to using a 4-point Likert scale indicating the frequency of these experiences during childhood. Because other measures used in this study, including the Family Involvement Questionnaire (Fantuzzo, Tighe \& Childs, 2000) and the Epistemic Curiosity Scale (Litman, 2008) use 4-point Likert scales that assess frequency of behaviors, I also chose to use a 4-point Likert scale (1-4) to reduce cognitive load for participants when they answered questions. Participants were asked to respond to these items retrospectively, based on how often they participated in these activities throughout their childhood. Six of the items in the checklist are activities related to science, whereas the remaining four items are general non-science activities that participants might have experienced as children. Only the scientific experiences were scored and counted for purposes of analysis. Thus, scores could range from 6 to 24 . In the current sample, the internal consistency of this scale was adequate, $(\alpha$ $=0.76)$.

Family involvement questionnaire. Fantuzzo, Tighe, and Childs (2000) developed a 42item assessment of parental involvement in school and academic-related activities. The questionnaire assesses parental involvement in three main areas of school engagement: (a) homebased parental involvement in a child's education, (b) school-based involvement, and (c) homeschool conferencing. Fantuzzo et al. (2013) developed a short form of the Family Involvement Questionnaire (FIQ-SF) that assesses these same three areas of involvement. The questionnaire 
includes 21 items that can be responded to using a 4-point Likert scale (see Appendix B), and scores could range from 21 to 84. Reported internal consistency for the FIQ-SF was good ( $\alpha=$ 0.95; Fantuzzo et al., 2000).

Though parents or other caregivers completed the original questionnaire, the FIQ-SF was adapted for the purposes of this study to be answered by the participants and to be answered retrospectively. Each item in the FIQ-SF was modified in order for the wording of each question to indicate that participants would be answering regarding behaviors of their parents and caregivers, not themselves. For example, the item "I spend time with my child working on reading/writing skills" was reworded to be "My parent(s) spent time with me working on reading/writing skills.” In the current sample, the internal consistency was good $(\alpha=0.93)$.

Epistemic curiosity scale. Litman (2008) developed a 10-item self-report questionnaire to assess levels of curiosity and likelihood to engage in behaviors representative of curiosity. This questionnaire assessed how likely individuals were to seek out new experiences, engage in problem solving, and discover how things in their environments work. This questionnaire consists of questions that measure two different dimensions of curiosity, one pertaining to seeking out novel experiences and the other to solving problems.

As previously stated, many self-report measures of curiosity may lack validity because curiosity is difficulty to define, and thus asking participants to rate their own levels of curiosity as a trait may lead to inaccurate results. Rather than asking participants to report their own levels of curiosity, however, this rating scale asks participants to rate how often they engage in behaviors that are indicative of curiosity (e.g., "I feel frustrated if I can't figure out the solution to a problem, so I work even harder to solve it," "I can spend hours on a single problem because I just can't rest without knowing the answer"). When responding to each curiosity item, 
participants were instructed to respond about how they "generally feel" on a 4-point scale (see Appendix C). Scores could range from 10 to 40 on this measure. Reported internal consistency for the ECS was good ( $\alpha=0.87$; Litman, 2008). Furthermore, Litman (2008) suggested that the ECS was a valid measure of curiosity as the ECS is positively correlated with other measures of curiosity, and it is found more strongly related to measures of cognitive activity than to measures of sensation seeking, providing evidence of convergent and discriminant validity. In the current sample, the internal consistency of the ECS was good $(\alpha=0.84)$.

Persistence questionnaire. Lufi and Cohen (1987) developed the Persistence Scale for Children, a 40-item questionnaire to assess individual differences in persistence. This questionnaire contains 5 validity items and 35 items that can be answered as either true or false (see Appendix D). For some questions, a response of false indicates a response characteristic of persistence, whereas for other questions, a response of true indicates a persistent response. Each item was scored as either 1 or 0 , meaning that participants could receive scores of 0 to 35 on this scale. Whereas the original measure was used with children, for the purposes of the current study, items have been modified to reflect behaviors of college-age participants.

Like the measure being used to assess curiosity in this study, this questionnaire asks participants about specific behaviors in which they engage that are indicative of persistence rather than asking participants to rate their own levels of persistence or compare their levels of persistence with other people. Sample questions include "When I read a book, I do not like to take breaks until I finish it," (a response of "true indicates persistence) and "If I have started a game of chess and it seems like it is going to take a long time, I prefer to stop playing" (a response of false indicates persistence). To specifically assess persistence with regards to academics, this scale was modified and some items that were not related to academic persistence 
were removed (e.g., "I keep fishing until I catch a fish"). Reported internal consistency for the ECS was marginal ( $\alpha=0.66$; Lufi \& Cohen, 1987). Lufi and Cohen (1987) demonstrated validity of this scale by reporting significant correlations between the scale and the need-persistence measure of the Rosenzweig Picture Frustration Study, Locus of Control, and other measures. In the current sample, the internal consistency of the scale was poor $(\alpha=0.22)$.

Influence of role models scale. Basow and Howe (1980) developed the Influence of Role Models Scale, which assesses how influential various individuals have been in one's career decision-making. The scale lists various individuals including family members, teachers, and friends, and asks participants to rate each person on a scale of -3 to +3 , with negative numbers representing a negative influence or discouraging one from entering a specific career, positive numbers representing a positive influence or encouragement to go into a specific career, and zero representing a neutral influence or no influence.

Because the proposed study only assessed the influence of parents and teachers and not of other adults, family members, or peers, the scale only included items that assess the influence of these individuals rather than including other role models. Because students may have received differing levels of career support from teachers in different academic domains during high school, the scale was expanded in order for participants to be able to rate teachers from varying academic subjects rather than just one teacher. Participants used a 7-point rating scale to indicate how influential each of these individuals was in influencing career choices (see Appendix E). In Basow and Howe's 1980 study, no information about the reliability and validity of the scale was reported. However, Nauta et al. (1997) found alpha of .86. as well as a correlation between the Influence of role models scale and measures of self-efficacy. In the current sample, the internal consistency of the scale was marginal $(\alpha=0.61)$. 
Math self-efficacy scale. Betz and Hackett (1982) developed the Mathematics SelfEfficacy Scale (MSES), a questionnaire meant to assess self-efficacy in the area of math. This questionnaire contains three subscales that include task self-efficacy, course self-efficacy, and math problem self-efficacy. The task self-efficacy subscale asks participants to rate on a 10-point Likert scale how confident they feel in completing a variety of tasks involving mathematics application (e.g., determine the amount of sales tax on a clothing purchase). This subscale includes a total of 18 items. The course self-efficacy subscale asks participants to rate on a 10point scale how confident they would feel that they could complete various college courses with grade of an A or B. Lastly, the problems subscale presents participants with math problems and asks them to rate how confident their feel in being able to complete each problem. Kranzler and Pajares (1997) conducted determined acceptable internal consistency values. In this study, researchers also used a revised, 5-point Likert scale rather than using a 10-point scale.

In the current study, the revised 5-point scale was used for the ease of participants because many other scales being used in the current study also used 5-point scales. To assess both general math self-efficacy for use of math in daily life as well as math self-efficacy as it relates to college course confidence, the math tasks subscale and math course subscale were used.

To assess participants' science self-efficacy, the course subscale was amended to include science classes as well as math classes (see Appendix F, Part II). The scale was further amended to include courses not related to STEM as well (see Appendix F, part III). Additionally, the taskself-efficacy subscale was amended to include additional items related to the use of science in everyday life in order to assess participants' self-efficacy for understanding science concepts and using science in other situations as well. The final length of the amended questionnaire is 36 
task-related items and 40 course-related items for a total of 70 items (see Appendix F). A participant's score was calculated by determining the sum of their math self-efficacy score average, science self-efficacy score average, and science course efficacy score average, with each of these three sub-areas being weighted equally. Each subscale was weighted equally because there were more course self-efficacy items than science and math self-efficacy items, and researchers wanted to avoid unintentionally measuring general academic self-efficacy or general class/course self-efficacy. The total score for math self-efficacy was summed, then divided by 18 (the total number of items in this sub-scale). Thus the math score could range from 1 to 5 . The total score for science self-efficacy was summed, then divided by 18 (the total number of items in this sub-scale). Thus the science score could range from 1 to 5 . The course self-efficacy scale contained 23 STEM course items. The total score for these items was summed then dived by 23 , and thus, scores for the course scale could also range from 1 to 5 . The total scores for each of these three subscales were added, and thus total scores for the entire selfefficacy measure could range from 3 to 15. Reported internal consistency for the original Math Self-Efficacy Scale was good ( $\alpha=0.96$; Betz \& Hackett, 1982). In the current sample, the internal consistency of the expanded scale including science self-efficacy items and STEM course self-efficacy items was good $(\alpha=0.96)$.

STEM training questionnaire. Participants were also questioned about which careers they intended to pursue following college, or the careers they were already working in, including the extent to which their career choice would require training in STEM, as defined by the National Research Council (2014). Specifically, participants were asked to rate on a scale of 1-5 the extent to which their careers/expected careers involve training and responsibilities in mathematics, science, engineering, and technology (see Appendix G). Participants were asked if 
they previously had another college major/if they switched majors at all, and if so, what their previous major was. Responses to this questionnaire were validated by conducting an independent samples $t$-test. Specifically, participants majors were coded as either "STEM" or "not STEM" and a $t$-test was conducted to analyze whether those in STEM majors reported higher scores on this scale on average, as would be expected. Results of the $t$-test indicated that those in STEM majors did report significantly higher scores, $t(465)=-13.26, p<.001$. This results indicate that on average, those in STEM majors did report that their training involved science, technology, engineering, and math to a higher degree than those in non-stem majors. Participants were then asked to describe the barriers they have faced, if any, in their current college major/career. Participants who had changed majors/career paths were asked to describe the barriers they experienced in their past major/career. These were open-ended questions, and the responses were coded qualitatively. Finally, participants were asked how many years they have been interested in their current major or vocational field.

A qualitative coding scheme was developed following procedures outlined by Corbin and Strauss (2015) to examine the barriers that students experienced in their current and past college majors or careers. A preliminary a priori coding scheme was developed that included the types of barriers that have been commonly cited in the literature (Appendix J), such as economic, institutional, and social/relational barriers. Additional categories were added based on a preliminary reading of participant responses. The final coding scheme included four general categories: social barriers, institutional barriers, socioeconomic barriers, and personal barriers. Each of these general categories contained multiple specific sub-codes (see Appendix K). One researcher coded $100 \%$ of the data, and a second researcher coded $20 \%$ of the data. For past barriers (130 responses) inter-rater reliability was good (Cohen's $\kappa=.95)$. For current barriers 
(339 responses) inter-rater reliability was also good (Cohen's $\kappa=.89$ ). All disagreements were resolved by discussion of codes between the two coders.

Inquiry experiences in science classrooms questionnaire. To assess the type of teaching methods used by participants' most influential science teachers, participants were asked questions about the extent to which they experienced inquiry learning in their high school science courses. Specifically, participants rated using a 5-point Likert scale the frequency with which they engaged in various activities that encompassed aspects of inquiry learning, including asking questions and framing research questions, designing investigations, conducting investigations, collecting data, and drawing conclusions. Items in this questionnaire are based on an inquiry learning experiences in classrooms questionnaire developed by Campbell, AbdHamid, and Chapman, (2009) for both students to rate the extent to which they experienced these teaching methods, as well as for teachers to rate the extent to which they used these methods in their classrooms. For the purposes of this study, only the student version of the questionnaire was used and the questions were adapted to be responded to retrospectively (See Appendix H). Reported internal consistency for the scale was good ( $\alpha=0.82$; Campbell, Abd-Hamid, \& Chapman, 2009). To further build construct validity of the instrument, self-report data of inquiry experiences in classrooms were compared to observations of inquiry methods in these classrooms using the Reformed Teaching Observation Protocol (RTOP). In the current sample, the internal consistency of the scale was good $(\alpha=0.94)$.

Demographics questionnaire. This questionnaire gathered information regarding participants' age, gender, racial/ethnic background, family composition, parents' education, parents' vocations and training in STEM, household income, and academic major in college (see Appendix I). 


\section{Procedure}

Data were collected via an online Qualtrics survey. Participants were first presented with information about informed consent. Participants were asked to verify that they are at least 18 years old. After providing consent, participants were told that they would be asked to answer questions about childhood experiences, educational experiences, and behaviors they engage in as well as their career training and aspirations. Participants were informed that they may leave the study at any time if they no longer wish to participate, and that there would be no negative repercussions if they chose to leave.

After participants completed informed consent and verified that they were at least 18 years of age, participants were asked demographic questions. Next, participants were presented with the following measures: childhood science experiences questionnaire, family involvement questionnaire (short form), epistemic curiosity, persistence scale, influence of role models scale, math and science self-efficacy scale, STEM training questionnaire, and inquiry experiences in science classrooms questionnaire. Upon completion of these measures, participants were thanked for their time and provided with more information about the study, including a debriefing statement. At this time participants were also provided with a link to an optional gift card raffle.

\section{Ethical Considerations}

When completing the online survey, participants were not asked to provide any identifying information about themselves. Furthermore, only the researchers involved in this study had access to the responses of the online surveys to ensure further the confidentiality of participants' responses. Once data had been collected, only the primary researchers had access to the data. Participants were reminded that should they become fatigued at any point during the survey, they may voluntarily withdraw from the study at any time. Participants at the university 
from which students were being recruited were provided with contact information for Student Counseling Services should they want to seek counseling services after taking the survey. Participants were also provided with a written debriefing statement that provided them with additional information about the study and the contact information of the researchers conducting this study if they had any questions following the completion of the survey. 


\section{CHAPTER III: RESULTS}

\section{Descriptive Statistics}

Descriptive statistics as well as bivariate correlations were completed for all study variables based on a sample of 190 men and 277 women and are displayed in Table 1. Table 2 displays the means and standard deviations for the Family Involvement Questionnaire (FIQ-SF), Childhood Science Experiences questionnaire, the Epistemic Curiosity Scale, modified Influence of Role Models Scale, modified Math Self Efficacy Scale, modified Children's Persistence Scale, Inquiry Experiences in Science Classrooms Questionnaire, and STEM career aspirations scale.

On average men and women reported similar amounts of parental involvement in their childhoods as rated on the Family Involvement Questionnaire, $t(465)=-1.52, p=.13, d=-.14$. Additionally, men and women also did not have significant differences in the amount of informal science learning experiences they engaged in, $t(465)=-1.91, p=.06, d=-.18$. Men and women also did not differ in their ratings of how influential their high school math and science teachers were in influencing their career choice on the Influence of Role Models Scale, $t(465)=1.55, p=$ $.13, d=.15$. Furthermore, men and women also did not report significant differences in the amount of inquiry-based science learning experiences they engaged in during high school science courses, $t(465)=.52, p=.61, d=.05$. Men and women also did not significantly differ in their self-ratings of their own persistence, $t(465)=-1.28, p=.20, \mathrm{~d}=-.12$, or in self-ratings of their own math and science self-efficacy, $t(465)=.12, p=.91, d=.01$. However, on average, women rated themselves as being more curious than men, $t(465)=-2.34, p=.02, d=.22$. Additionally, men and women differed in their ratings of the degree to which their intended 
careers involve STEM, with men reporting that their intended careers involved more training in STEM than women did, $t(465)=2.79, p=.006, d=.26$.

\section{Model Testing}

The hypothesized models for men and women are presented in Figures 5 and 6 in Chapter I. A solid line between two predicted variables represents a predicted relation where a singleheaded arrow indicates a directional prediction (scores on variable A will predict variable B). Curved, double-headed arrows represent non-directional association and not a directional effect. No transformations were made to correct for skewness or kurtosis. I then proceeded to run structural equation modeling analyses on the 467 complete cases with no missing data. Ideally, the study would have employed 3 or 4 measures for each construct to allow for structural equation modeling with latent variables. Doing so, however, would dramatically increase the number of parameters to be estimated which would have increased the sample size requirements beyond the resources available for the current study. Sample sizes were planned on the basis of Christie (2017) with the expectation that many of the parameters would be constrained to be equal across gender groups. This assumption was central to the sample size planning with 8-10 participants per parameter, but this limitation unfortunately precluded testing a configural model where no parameters were constrained to be equal between groups. Christie (2017) also found many notable differences between men and women for some of the same study variables which would preclude a single-group analysis as the parameters estimated would not accurately describe neither women nor men.

I estimated parameters of all models using the general least squares method, which allows parameters to be estimated when variances of the observed constructs in the models are not equal (Ullman, 2007). Ullman (2007) provides criteria for determination of model fit. A model is 
assumed to fit the data depending, in part, on fit indices scores. The minimum value for the comparative fit index (CFI) and normed fit index (NFI) is .90, although a value of .95 is preferred, whereas the root mean square error of approximation (RMSEA) and standardized root mean square residual (SRMR) should be below .05 (Ullman, 2007). The hypothesized models for men (Figure 7, top panel) and women (Figure 7, bottom panel) did not fit the data, $\chi^{2}(32, N=$ $476)=391.62, \mathrm{CFI}=.34, \operatorname{RMSEA}=.22, \operatorname{SRMR}($ women $)=.17, \operatorname{SRMR}($ men $)=.14$ and $\mathrm{NNFI}=$ .13. 

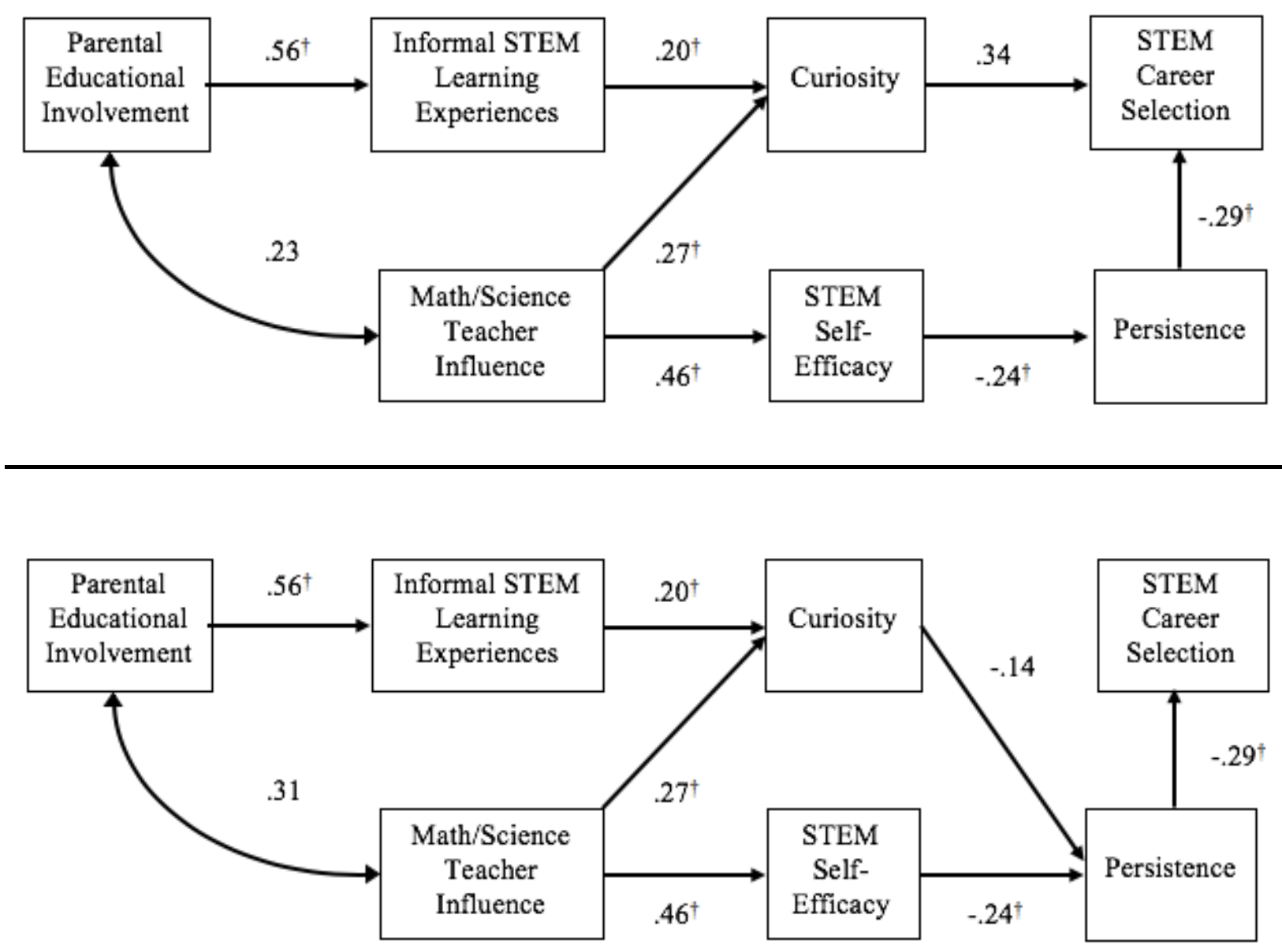

Figure 7. Results of original proposed models for men (top panel) and women (bottom panel) of the influences of parental educational involvement, informal science learning experiences, teacher influence, STEM self-efficacy, persistence, and curiosity on STEM career aspirations. Parameters constrained to be equal are marked with a dagger. Standardized path coefficients are reported.

Although the hypothesized models did not fit the data, there were some hypothesized relations within each model that were significant. For both men and women, parental educational involvement was a strong predictor of informal science learning experiences. This effects was consistent with Christie's (2017) results as well as previous literature in the area of parental involvement. There was also a moderate to strong effect of teacher influence on STEM self- 
efficacy for both men and women, consistent with previous literature indicating teachers as important sources of fostering self-efficacy in STEM. For both men and women there was a small to moderate influence of informal STEM learning experiences and teacher influence on curiosity. For men in particular, there was also a moderate effect of curiosity on STEM career aspirations. For women, curiosity was also predictive of lower levels of persistence, with a small effect size.

Although some of the hypothesized predicted relations between variables were significant in the tested model, some of the hypothesized relations had only a small effect size, and some predicted relations were in the opposite direction than hypothesized. Specifically, for both men and women, higher levels of STEM self-efficacy would predict higher persistence. However, the relation between these two variables was negative. Additionally, it was hypothesized that persistence would predict higher levels of STEM career aspirations for men and women, but this relation too was negative. Further, for women, contrary to the hypothesis that curiosity would predict higher levels of persistence, curiosity predicted lower levels of persistence.

In an attempt to develop a better fitting model, I performed model modifications post hoc. For each model output, I reviewed the standardized path coefficients and modification indices to evaluate the effect of and relaxing parameter constraints (i.e., parameters constrained to be equal for both men and women or parameters constrained to be zero) for better model fit. Model modifications were also made, in part, based on theoretical conceptualization of the relations between the variables being examined in the study. Thus, the order of variables was also changed to reflect different predictive relations between variables during model modification.

Overall, 17 different models were tested before models for both men and women that fit that data were found. Parameters previously constrained to be equal to zero (ie not included in 
the model) were considered for inclusion on the basis of their modification index, but only a single parameter was considered for inclusion at a time. Eliminating the constraints for parameters being equal for men and women was considered using modification indices as well. Parameters that were initially unconstrained across gender groups were evaluated for a potential constraint when the raw parameter constraints were highly similar in value. Parameters with a low t-value (raw estimate divided by standard error) or with standardized values below .10 were considered for removal from the model by constraining them to be equal to zero. Given the exploratory nature of making changes and given the interdependence of parameter estimates on the model being estimated, only one parameter change was made at a time. This more conservative approach to model modification, did, however, increase the total number of models estimated. The final models, shown below, were reorganized based on my conceptualization of the modification indices from LISREL output and conceptual understanding of the study variables. All exogenous variable covariances are included in the models and all model specification error terms are uncorrelated in the models. The model in Figure 8 was acceptable and fit the data, $\chi^{2}(30, N=467)=48.91, \mathrm{CFI}=.97, \mathrm{RMSEA}=.05, \mathrm{SRMR}($ women $)=.039$, $\operatorname{SRMR}($ men $)=.039$, and NNFI $=.95$. 

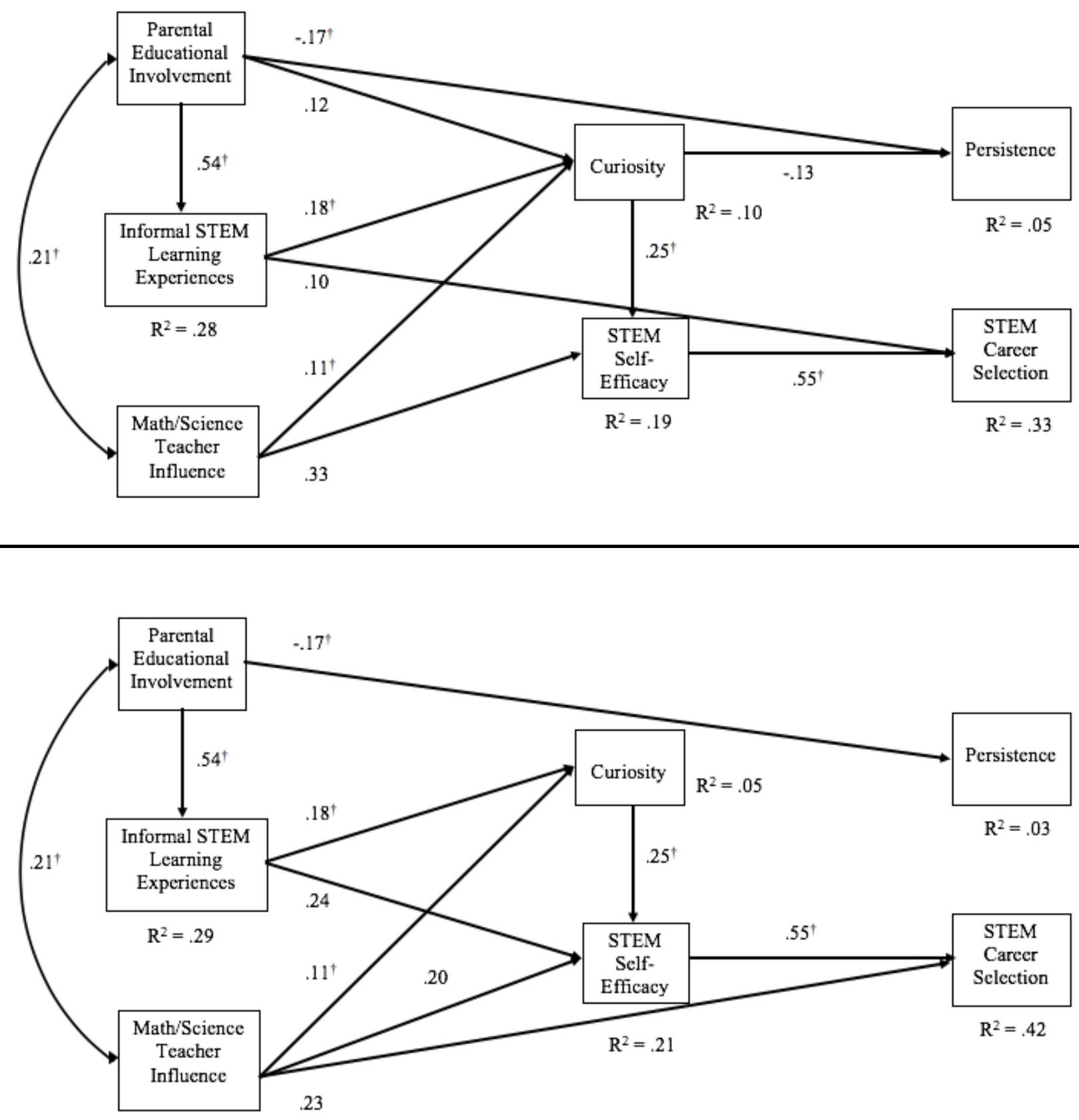

Figure 8. Finalized acceptable model for men (top panel) and women (bottom panel) of the influences of parental educational involvement, informal science learning experiences, teacher influence, STEM self-efficacy, persistence, and curiosity on STEM career aspirations.

Parameters constrained to be equal are marked with a dagger. 
For men, parental educational involvement was predictive of higher levels of curiosity and informal STEM learning experiences, and predictive of lower levels of persistence. Higher frequency of informal STEM learning experiences was predictive of higher levels of curiosity and aspirations to pursue a STEM career. Positive influence of high school math and science teachers was predictive of curiosity and STEM self-efficacy. Higher levels of curiosity predicted higher levels of STEM self-efficacy but predicted lower levels of persistence. Lastly, STEM selfefficacy directly predicted aspirations to pursue a STEM career.

For women, parental educational involvement was predictive of higher frequency of informal STEM learning experiences in childhood and of lower levels of persistence. Informal STEM learning experiences predicted higher curiosity and higher STEM self-efficacy. Curiosity was also a direct predictor of STEM self-efficacy. The positive influence of high school math and science teachers predicted curiosity, STEM self-efficacy, and aspirations to pursue a STEM career. Lastly, STEM self-efficacy also directly predicted aspirations to pursue a STEM career.

There were a number of similar paths between the final models for men and women. For both men and women, those whose parents were highly involved in their education were more likely to have a higher frequency of informal science learning experiences during childhood. Furthermore, for both men and women, higher ratings of parental involvement in their education during childhood were predictive of lower self-ratings of persistence. For both genders, higher frequency of informal science experiences predicted higher self-ratings of curiosity. For both men and women, higher ratings of math and science high school teacher influence were predictive of higher self-ratings of curiosity as well as higher self-ratings of math and science self-efficacy. Lastly, higher likelihood of STEM career aspirations was predicted by higher ratings of math and science self-efficacy for both men and women. 
There were also a number of ways in which the final models differed. For men only, higher self-ratings of curiosity were predictive of lower self-ratings of persistence. For men only, higher parental educational involvement also predicted higher self-ratings of curiosity. For women only, frequency of informal science learning experiences in childhood was predictive of higher math/science self-efficacy. For women, math and science teacher influence was also predictive of higher likelihood of career aspirations involving STEM, whereas for men only, more frequent childhood informal science learning experiences were predictive of STEM career aspirations.

To understand the role that science teachers' teaching methods, particularly those using inquiry-based teaching methods in high school science courses play in predicting aspirations to pursue STEM careers, additional modifications were made to the model above (Figure 8) to add the variable of inquiry learning experiences to the model for both men and women. This variable was not included in initial analyses because it was not included in Christie's (2017) study, and thus the current study aimed to first confirm Christie's findings before adding an additional new variable to hypothesized models. Based on a theoretical understanding of inquiry learning experiences from the previous literature in this area, it was hypothesized that both men and women who had more frequent inquiry learning in their high school science courses would have higher self-ratings of math and science self-efficacy. In other words, I hypothesized that inquirylearning experiences would predict STEM self-efficacy in both the male and female models, with the parameter constrained to be equal.

I estimated parameters of all models using the same method described above, with the same criteria for determination of model fit. The hypothesized models for men and women with the addition of inquiry-based learning (IBL) experiences predicting STEM self-efficacy did not 
fit the data, $\chi^{2}(42, N=476)=105.80, \mathrm{CFI}=.92, \mathrm{RMSEA}=.08, \operatorname{SRMR}($ women $)=.055$, $\operatorname{SRMR}(\operatorname{men})=.057$ and NNFI $=.89($ see Figure 9$)$. 

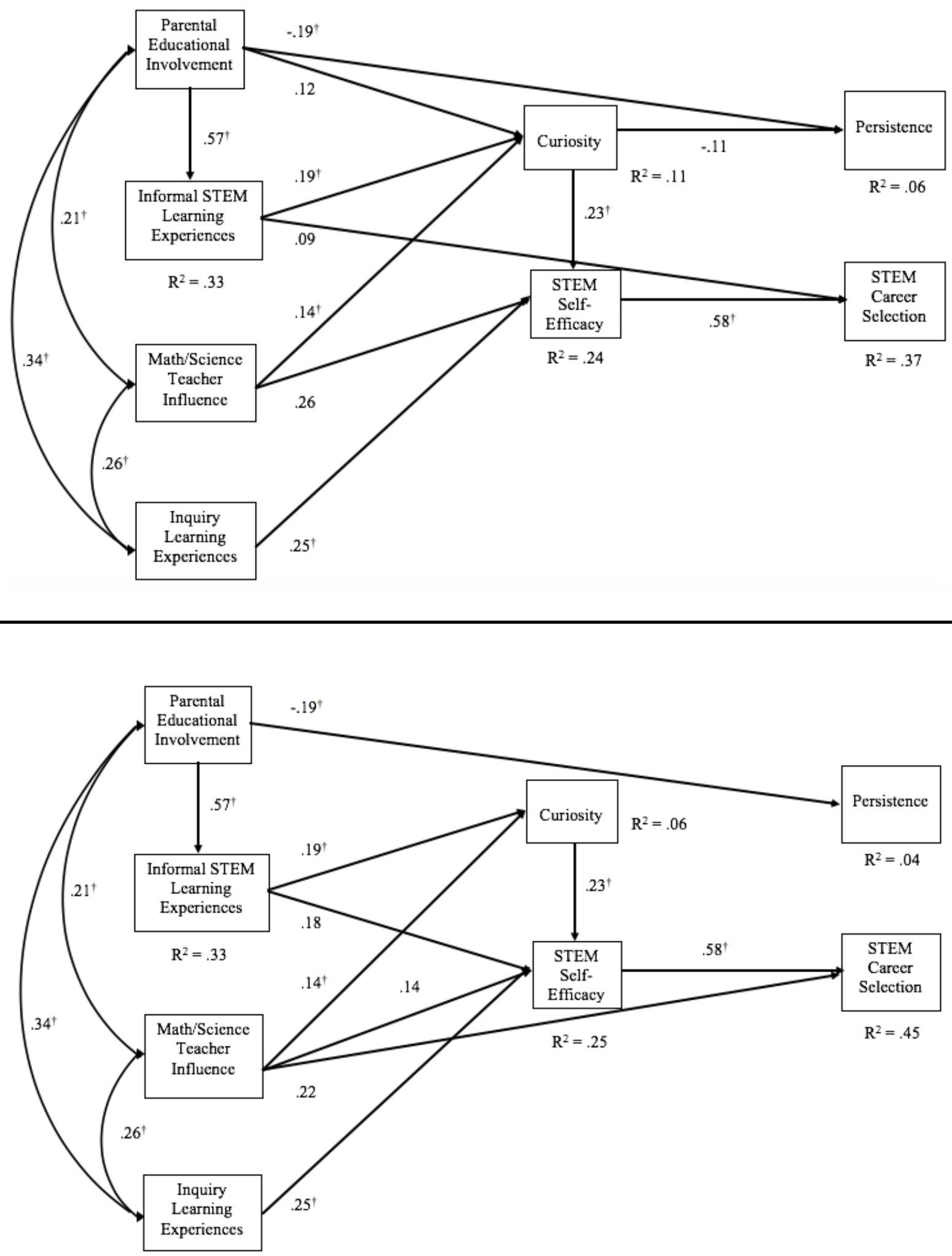

Figure 9. Results of proposed models for men (top panel) and women (bottom panel)

including IBL. Parameters constrained to be equal across gender are marked with a dagger. 
In an attempt to develop a better fitting model, I again performed model modifications post hoc. For each model output, I reviewed the standardized path coefficients and modification indices to evaluate the effect of relaxing parameter constraints for better model fit. Model modifications were also made again, in part, based on theoretical conceptualization of the relations between the variables being examined in the study.

Overall, five total models were tested before models for both men and women that fit that data with the addition of the inquiry learning experiences variable were found. The final models, shown below in Figure 10, were reorganized based on my conceptualization of the modification indices from LISREL output and conceptual understanding of the study variables. The model in Figure 10 was acceptable and fit the data, $\chi^{2}(41, N=467)=74.04$, CFI $=.96$, RMSEA $=.059$, $\operatorname{SRMR}($ women $)=.04, \operatorname{SRMR}($ men $)=.051$, and NNFI $=.94$. 

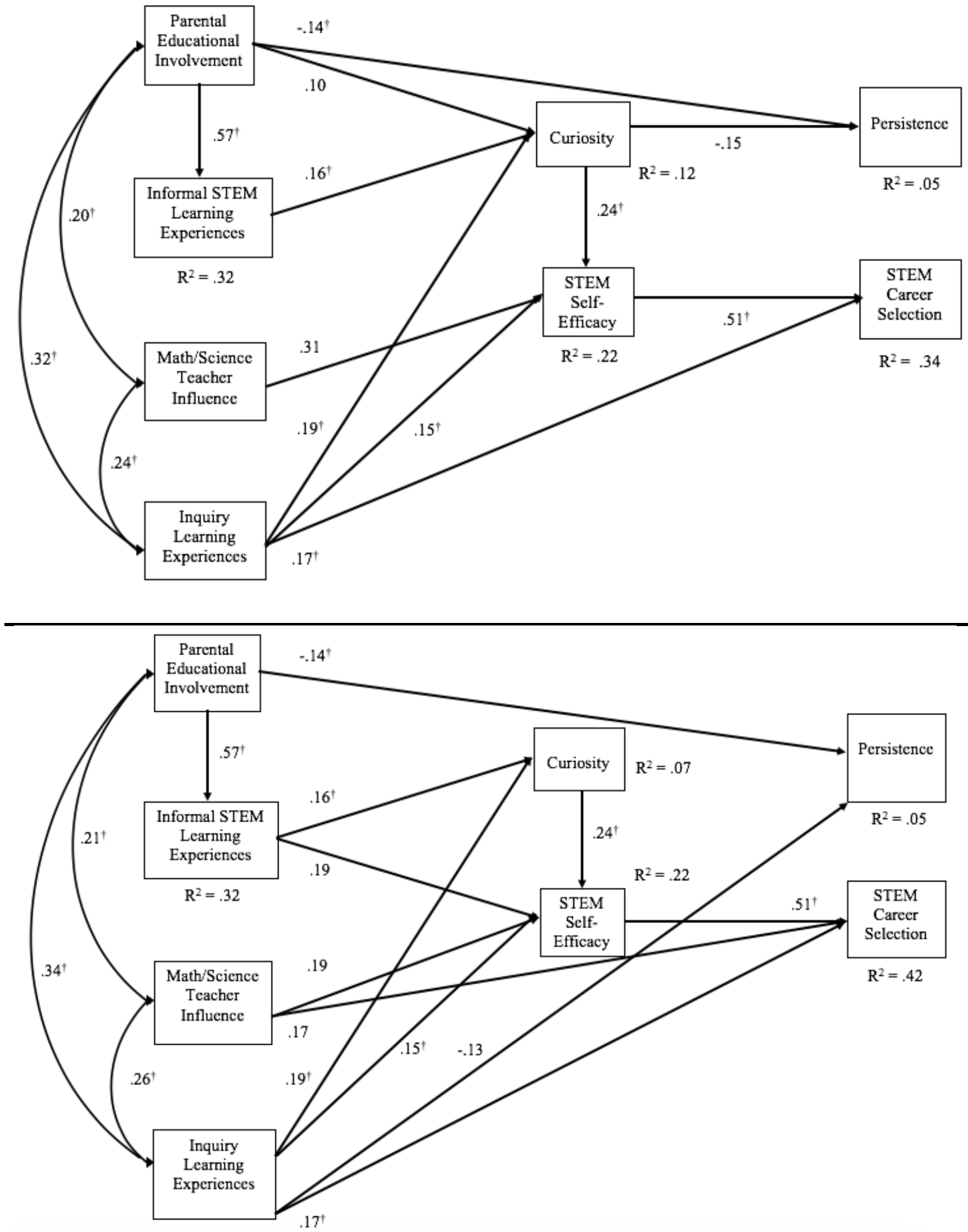

Figure 10. Finalized acceptable model for men (top panel) and women (bottom panel) including IBL. Parameters constrained to be equal across gender are marked with a dagger. 
There were multiple modifications to the original acceptable model that were altered when the construct of inquiry learning was explored within the model. First, experiences with science teachers in high school who utilized inquiry-based approaches were predictive of higher self-ratings of curiosity and math/science self-efficacy for both men and women. Furthermore IBL experiences were also predictive of higher aspirations to pursue a STEM career. For women only, higher frequency of IBL in high school was predictive of lower self-ratings of persistence. With the addition of inquiry learning into the model, math and science teacher influence was no longer predictive of curiosity for men nor women as it had been in the finalized acceptable model in Figure 10, and higher frequency of childhood informal science learning experiences were no longer predictive of higher aspirations to pursue a STEM career for men.

\section{Mixed-Methods Analysis of Barriers}

Only a subset of the overall sample reported experiencing barriers in their past $(N=130)$ and current $(N=339)$ fields of study. Appendix $\mathrm{J}$ includes the final coding categories, and the frequencies of past and current barriers are reported in Appendix: Table 3. Because of a small sample size of those reporting barriers and the number of coding categories, there were few analyses that could be conducted to make comparisons with respect to the specific types of barriers experiences by men versus women and those in STEM fields and those in other majors. Instead, I summed the overall number of barriers reported by participants and analyzed whether the number of past and current barriers varied by gender and current major or field of study.

For barriers experienced in one's past field of study, I conducted a Gender x Major (STEM vs. non-STEM) analysis of variance. There was a significant main effect of Gender, $F(1$, $105)=4.89, p=.03$. On average, women reported more experienced barriers $(M=1.36, S D=$ $.63)$ in their past major than men $(M=1.13, S D=.34)$ regardless of whether or not their past 
major was STEM or non-STEM. There was no main effect of Major, $F(1,105)=.001, p=.98$, nor an interaction between Gender and Major, $F(1,105)=.59, p=.44$.

For barriers experienced in one's current field of study, there was also a significant main effect of Gender, $F(1,223)=12.00, p=.001$. Women reported a significantly higher frequency of barriers $(M=1.37, S D=.63)$ towards achieving their career-related goals than men $(M=1.12$, $S D=.39)$, regardless of their chosen field or major. There was no main effect of Major, $F(1$, $105)=1.08, p=.30$. It was hypothesized based on the past literature that women in STEM fields might report significantly more barriers than other groups. However, there was not a significant interaction between Gender and Major, $F(1,223)=2.31, p=.13$. 


\section{CHAPTER IV: DISCUSSION}

\section{General Discussion}

The current study explored the role that various childhood and adolescent experiences with formal and informal STEM learning as well as individual difference variables play in predicting gender differences STEM career aspirations. In particular, I examined the relations among measures of parental educational involvement, childhood informal science learning opportunities, the influence of math and science teachers on career choice, experience with IBL in high school science courses, individual differences in curiosity and persistence, and the outcome variables of the extent to which one's career choice involved training in science, technology, engineering, and math.

Initially, I predicted that these variables would influence STEM career choice in different ways for women and men based on a review of the literature. For women, I predicted that high parental educational involvement would predict higher frequency of informal STEM learning experiences in childhood. I hypothesized that higher frequency of engagement in these learning experiences would then predict higher levels of curiosity among women. I also predicted that women who rated their high school math and science teachers as being more influential in their career decision making would also have higher levels of curiosity and would also have higher levels of self-reported self-efficacy in math and science. I then predicted that both higher levels of curiosity and higher levels of STEM self-efficacy would be predictive of higher levels of persistence, and that higher persistence would predict higher STEM career aspirations among women.

Although my hypotheses for men were similar in many ways to my hypothesized model for women, my hypotheses for men were slightly different with regards to the variables of 
curiosity and persistence. Based on the results of Christie (2017), I did not predict that higher ratings of curiosity would predict higher ratings of persistence as I did with women. Rather, I predicted that higher ratings of curiosity would directly predict higher likelihood of aspirations to choose a STEM career for men as would persistence.

Results of the initial models indicated that the hypothesis that parental educational involvement would predict higher frequency of informal science learning for both men and women was significant. This effect was consistent with previous studies and further indicates that parents play a role in providing access to informal learning experiences in STEM for their children at young ages. Furthermore, the hypothesis that high school math and science teacher influence would be predictive of STEM self-efficacy was also significant for both men and women, indicating that teachers play an important role fostering self-efficacy in STEM subjects. For both men and women informal STEM learning experiences and teacher influence predicted curiosity, but only with a small to moderate effect size. The hypothesis that curiosity was predictive of STEM career aspirations for men was supportive, but also with only a moderate effect size. For women, the hypothesis that curiosity was predictive of lower levels of persistence was supported, but with a small effect size.

Contrary to the hypothesis that higher levels of STEM self-efficacy would predict higher persistence for both men and women, STEM self-efficacy predicted lower persistence. Additionally, the hypothesis that persistence would predict higher levels of STEM career aspirations was not supported and this relation was also negative. Lastly, for women, the hypothesis that curiosity would predict higher levels of persistence was not supported, and curiosity predicted lower levels of persistence for women in this model. 
Fit indices of these models for both men and women indicated that neither of these models fit the data collected. However, through exploratory analyses, I modified these models to yield better fitting models that explained the relations among these variables. Furthermore, once models with good fit had been identified, I performed additional model modifications to identify how the variable of inquiry learning experiences related to the other variables in the study.

Specifically, exploratory analyses indicated that for women, parental educational involvement predicted engagement in childhood informal science learning experience, which predicted higher levels of both curiosity and STEM self-efficacy. Parental educational involvement was also predictive of lower levels of self-reported persistence. Curiosity was also a direct predictor of STEM self-efficacy for women. Math and science teacher influence did predict math and science self-efficacy but was also a direct predictor of STEM career aspirations for women. STEM self-efficacy was also a direct predictor of STEM career aspirations. Lastly, higher frequency of inquiry learning experiences in science courses in high school was predictive of higher levels of curiosity, STEM self-efficacy, STEM career aspirations, and predictive of lower levels of persistence.

Exploratory analyses indicated that for men, higher levels of parental educational involvement predicted higher levels of both informal science learning experiences in childhood and higher levels of curiosity. Furthermore, higher parental educational involvement also predicted lower levels of persistence for men, as it did for women. Additionally, for men, higher levels of curiosity were predictive of lower levels of persistence. As with women, higher levels of curiosity were predictive of higher levels of STEM self-efficacy. Additionally, math and science teacher influence on career choice was also predictive of higher levels of STEM selfefficacy. STEM self-efficacy was a strong, direct predictor of STEM career aspirations. Lastly, 
IBL experiences in high school science courses were predictive of higher levels of curiosity, STEM self-efficacy, and STEM career aspirations.

\section{Parental Educational Involvement}

\section{Parent Involvement and Persistence}

In both the final models for men and women, higher parental educational involvement directly predicted lower self-reported scores in persistence. This result was not hypothesized and was the opposite direction than I predicted. Initially, I hypothesized that for women, parental educational involvement would predict both early childhood informal science learning experiences and curiosity, and that higher levels of curiosity would predict higher levels of persistence. It was surprising then, that those whose parents were more involved in their education had lower scores on a measure of persistence.

One possible explanation for this result is the effects of parents who are overly involved in their children's learning, which may inhibit later persistence. In recently years, parents labeled "helicopter parents," or those who are overly active, highly involved, and often make decisions for their children while intervening in their lives have received increased attention in the child developmental research literature. Many researchers have begun to examine the effects that this parenting style has on children later in life, especially as they reach adulthood. Some researchers have suggested that this style of parenting may affect children's motivation and dependence on parents, and that children with "helicopter parents" may be more likely to be dependent on parents and may have lower self-efficacy (Reed et al., 2016).

Considering the reported effect that highly involved parents who are more likely to intervene has on their children's self-efficacy, it also possible that this parenting style affects persistence. In other words, children raised with parents who were more likely to intervene in 
school-based tasks and aid in academic situations may be less likely to persist because of childhood socialization factors associated with highly involved parents. This is not to say that all highly involved parents are "helicopter parents," rather that perhaps children with highly involved parents may have lower ratings of persistence because they have been conditioned to seek support in situations where others, who have not been socialized to rely on help, might persist. The relationship between parental educational involvement and later persistence is an area that would benefit from further research.

\section{Parents Fostering Curiosity}

One way in which the final models indicated that parental educational influence differed across gender of the child was that parental educational involvement predicted higher levels of self-reported curiosity for boys but not for girls. One potential explanation for this effect is the different way that boys are girls are treated and socialized in educational settings. In other words, it is possible that the way parents treat boys fosters higher levels of curiosity, whereas this effect might not exist for girls.

As previously discussed, some researchers have proposed that even when parents are highly involved in their child's education, parents treat boys and girls differently in these settings. I previously summarized the results of Crowley, Callanan, Tenenbaum, and Allen (2001), in which researchers examined the interactions of parents and children in a museum. Crowley et al. (2001) found that parents asked more open-ended question to male children and provided them with more causal explanations on average during visits. It is possible that these types of conversations and inquiry-like guidance by parents cultivate stronger curiosity about science learning or stronger general curiosity for male children. Although Crowley and colleagues' (2001) study was conducted in a museum, it is entirely possible that these gendered 
interactions between parents and children generalize to other settings, which may compound potential gender-differential effects that parental educational involvement has on curiosity.

\section{Childhood Informal Science Learning Experiences}

Another result that differed for men and women was that informal science learning experiences were a direct predictor of STEM career aspirations for men. For women, however, informal science learning predicted self-efficacy, and self-efficacy predicted STEM career aspirations. In other words, higher frequency of informal STEM learning experiences predicted higher STEM self-efficacy, which then predicted higher likelihood of entering a STEM career for women. It is not extremely surprising that early exposure to science learning experiences may be predictive of entry into a STEM career for men. As previously discussed, children may gain interest in and excitement about science topics from attending museums, aquariums, and other STEM-related experiences in childhood, and the research literature has demonstrated that these experiences have the potential to influence their later interest in these topics later in life (e.g., Johnson, 1987).

It was unexpected, however, that informal science learning predicted self-efficacy, then self-efficacy predicted career selection for women whereas informal science learning was a direct predictor of career selection for men. One possible explanation that may explain why these informal STEM learning experiences predict STEM self-efficacy for women and not men is the lack of STEM exposure that girls experience in other settings in childhood. As previously stated, toys involving STEM are more often marketed towards boys, and thus, male children may have opportunities to derive STEM self-efficacy in many other situations, whereas these informal experiences may be especially important for girls. Another explanation for this effect is because women experience more barriers in STEM fields and in education related to STEM across 
development, than men do. For this reason, women's belief in their ability to be successful in STEM may be especially important in the face of barriers that threaten success in these fields.

As researchers continue to examine the role that informal science learning experiences play, the pathway indicating that higher frequency of informal science enrichment experiences predicts higher STEM self-efficacy later in life is an important area for future study. Knowing that these experiences may increase STEM self-efficacy, and that higher self-efficacy is strongly predictive of entry into STEM careers, researchers should continue to examine the factors in these settings that foster learning, confidence, and self-efficacy for women and other underrepresented groups in STEM. Furthermore, knowing that these experiences do indeed play a role in self-efficacy and STEM career aspirations, professionals working in these settings should continue to make access to these experiences a priority for children from different socioeconomic backgrounds.

\section{Importance of STEM Self-Efficacy}

\section{STEM Self-efficacy Predicting STEM Career Aspirations}

A predictive relation that existed in both the final models for men and women was STEM self-efficacy predicting STEM career aspirations. Path coefficients for both men and women indicated that this was a particularly strong predictive relation. Although this result was not originally hypothesized, it is one that conceptually makes sense given the previous research literature in vocation aspirations as well as a theoretical understanding of both of the variables of STEM self-efficacy and STEM career aspirations.

The measure used to assess STEM self-efficacy in the current study asked participants to rate their confidence performing a variety of tasks directly related to application of knowledge in the areas of science, technology, engineering, and math. Furthermore, participants also rated 
their belief that they could receive a strong passing grade in college-level courses in these subjects. In the STEM training questionnaire, participants then rated the degree to which their intended career involved training in these four subjects. It is reasonable to assume that those who experienced more training in these subjects would also self-rate a higher degree of confidence in performing tasks in these subjects compared to students with less experience in STEM coursework. Furthermore, consistent with current and past literature in vocational choice, it is reasonable to assume that most students would choose career paths involving subjects that they feel confident and effective in. Therefore, is it important for researchers to continue to examine and understand the factors that increase STEM self-efficacy to further diversify participation in STEM fields.

\section{Teacher Influence on Self-Efficacy}

Initially, I hypothesized that math and science teacher influence on career choice would be a predictor of STEM self-efficacy for both men and women. Although this hypothesis was supported for men and women, the final models indicated that this effect appeared to be stronger for women than for men. One reason that a stronger effect for women may exist is because teachers, especially those who are also women, may be especially important influences who serve as role models for girls as they pursue STEM careers (Christie, 2017). As previously discussed, past studies have demonstrated that women, and in particular women of color, have cited their teachers as being particularly strong influences and reasons why they chose to go into STEM careers (Maple \& Stage, 1991). I previously proposed that those in underrepresented groups might look to teachers from their own group memberships as role models in STEM due to low representation of these groups in the field. In other words, students from groups not traditionally represented in STEM may not have as many other STEM role models as men. It is 
also possible, then, that if these teacher relationships or teacher influence is of more importance to those from underrepresented groups, including women, that teacher influence is also a stronger source of self-efficacy.

There are likely other explanations as to why math and science teacher influence is a stronger predictor of STEM self-efficacy for women than for men. Regardless of the explanation, this is a topic that deserves more attention in the current research literature, particularly because, as previously stated, STEM self-efficacy is a strong predictor of aspirations to pursue a STEM career. Knowing that teachers have the potential to directly influence girls' self-efficacy for STEM subjects makes this area a strong candidate for potential intervention and future change to continue to bolster girls' self-efficacy to increase female representation in STEM career fields.

\section{Classroom Inquiry Learning Experiences}

\section{Inquiry and Curiosity}

In the final model in which inquiry-based learning experiences were also added into the model, inquiry teaching methods used by high school science teachers predicted multiple different variables for both men and women. One such relation was that IBL experiences were predictive of higher levels of curiosity for both men and women. As previously discussed, the current research literature surrounding inquiry-based teaching methods has demonstrated that students who receive more instruction in science courses using inquiry methods are more proficient on average employing the scientific method, including forming their own scientific hypotheses (Minner, Levy, \& Century, 2010). It is possible that exposure to these experiences might foster skills related to asking more questions and forming more hypotheses in a variety of situations, and thus, students who engage in more question-asking and hypothesis-forming may have higher levels of curiosity than those not trained in inquiry. 


\section{Inquiry and Persistence}

One result that was not initially hypothesized was that higher frequency of IBL experiences was predictive of lower levels of persistence for women. In addition to having not hypothesized this effect, I was also surprised by the direction of the effect, as I would have expected that more inquiry-based science-learning experiences would predict higher levels of persistence among women.

One potential explanation for the effect is that it is possible that the relationship between higher frequency of inquiry learning and lower persistence is mediated by experience of barriers in STEM settings. It is known from the previous literature that women in STEM tend to experience more barriers in these settings than other fields, and reported barriers increase and worsen over time (Fouad et al., 2010). Thus, it is possible that reports of more frequent inquiry learning came from those women who experiences more science courses/more STEM activities in general, and may have experienced more barriers, which lowered persistence.

Another potential reason for higher frequency of IBL in high school predicting lower levels of persistence during college is that pedagogy that is typically used in instruction in high school often does match instruction at the post-secondary level. Specifically, although many high school science teachers have incorporated inquiry-based teaching methods into secondary science education courses, many college-level science courses still utilize direct instructional approaches and lower levels of IBL. Thus, students with higher exposure to IBL in high school may have difficulty or lower levels of interest during their college science courses, and thus be less likely to persist in STEM because of pedagogical "mismatch" between high school and college. These are only a few potential explanation for this effect and many other explanations may exist. 


\section{Inquiry and Self-efficacy}

In both the final models including IBL experiences in high school science courses for men and for women, inquiry learning was a predictor of higher self-reported levels of STEM self-efficacy. Considering the skills that inquiry learning aims to promote among students, this result was not surprising. Specifically, the scale used in the current study measured the extent to which participants engaged in asking questions and framing research questions, designing investigations, conducting investigations, collecting data, and drawing conclusions. It is likely that students who engaged in higher frequency of these experiences developed greater independence related to asking and answering scientific questions, and thus developed greater self-efficacy in science courses that generalized to other areas of STEM as assessed in the STEM self-efficacy scale.

\section{Barriers Experienced by Women}

When examining the barriers experienced by men and women in STEM fields and nonSTEM fields, I had initially predicted based on previous literature that there would be a significant interaction between gender and major, and that women in STEM fields would report significantly more barriers than men in STEM and women in non-STEM fields due to lower gender representation in STEM. However, there was no such interaction, but there was a main effect for gender. In other words, regardless of whether or not women were in STEM majors, they tended to report a higher number of barriers experienced than men, both in their past and current majors.

Despite not finding an interaction for gender and major in the results of the current study, there is still significant evidence from the literature to suggest that women in STEM experience more barriers due to lack of representation than women in fields in which they are well- 
represented. One reason that such an effect may not have been found in the current study was because only a fraction of the overall sample responded to the open-ended questions about barriers experienced, and thus the total sample size for these analyses was smaller. Explanations as to why a fewer subsample answered these questions include that these were the last questions in the survey, and participants could have been experiencing fatigue. It is also possible that those who did not experience barriers they could think of to report did not answer these questions. The significance level for this interaction $(p=.13)$ was approaching marginal significance, and perhaps with a larger sample size, I might find the hypothesized significant interaction.

Although I had not hypothesized that there would be a main effect of gender, I was not surprised by this result. After further consideration of the barriers women were reporting and post-hoc examination of some of the qualitative responses as well as the literature, it became clear that STEM fields are not the only fields in which women are underrepresented and experience barriers. For example, some of the female participants who reported barriers related to gender reported being some of the only women in majors or classes related to business management, marketing management, or law enforcement. Furthermore, even in fields, majors, and classes in which women are not underrepresented, it is possible and even likely that women may still experience gender bias or more difficulty attaining their career goals, simply because of institutionalized sexism present in academic and career settings.

\section{Limitations and Future Directions}

\section{Exploratory Analyses}

Although I developed path models that fit the data, these results were exploratory, and must be interpreted with caution. Specifically, the results found in the exploratory models in this study may not be replicable, and may have included results that were false positives. In order to 
confirm the generalizability of these results, the current study would need to be replicated in order to determine if the finalized models would fit newly collected data. Furthermore, in future studies, ideally a configural model would be tested.

\section{Retrospective Report}

For some of the measures used in the current study participants were asked to respond retrospectively regarding experiences they had during childhood. It is possible that because participants had to recall events and situations that happened years ago, their responses did not completely and accurately reflect their parents' engagement in their education, the frequency with which they attended informal science learning experiences, inquiry learning experiences in high school science courses, or their teachers' support during their school years. Furthermore, because this study utilized retrospective reports and did not follow participants through these experiences longitudinally, causal inferences about relations between variables analyzed in this study cannot be inferred. Although time-consuming, the key way to address this issue in future research would be through longitudinal research methods.

\section{Sample}

One of the primary limitations of the current sample was that it lacked racial and ethnic diversity. The sample in this study was primarily white/European-American. Therefore, results from this study may not generalize to predict the career aspirations of other racial/ethnic groups. As previously discussed, students from underrepresented racial/ethnic groups in STEM fields often experience different and/or more frequent barriers than white students do, and thus, may be influenced by predictors of STEM career entry in different ways than white students are. Research that systematically targets the recruitment of students from diverse racial/ethnic groups 
would be necessary to understand the differences in predictors and barriers that may occur among students from these groups as they pursue STEM careers.

\section{Measuring STEM Self-Efficacy}

Although, as previously stated, the current study expanded upon the math self-efficacy scale by adding items related to the use and application of science and technology, this measure was not psychometrically validated. In the future, it would best if this measure was validated prior to use, and thus, the results of the models reported in this study must be interpreted with caution, especially when considering the role that STEM self-efficacy plays in predicting other variables.

\section{Mixed-Methods Analyses}

One potential limitation of the mixed methods analyses examining the barriers that students experience in their past and current majors was that students from all grade levels were analyzed as part of the same group. The current study did not examine whether students in different grades, either earlier or later in their college careers might experiences more careerrelated barriers. Furthermore, all STEM majors were also analyzed together in the current study, so it is unknown if students in specific STEM fields might be experiencing more barriers. It would be beneficial to examine the effect of barriers in different grades, and in different majors in future research.

\section{Reliability of Persistence Measure}

A major limitation of the measure used in this study to measure persistence was the internal consistency in the current sample was poor $(\alpha=0.22)$. Therefore, any interpretation of persistence in the current study should be done with caution. It is important for future studies 
examining STEM career persistence to use a more valid and reliable measure of persistence, and it would be beneficial for a measure of career persistence to be developed in the future.

\section{Strengths of the Current Study}

\section{Sample}

One strength of the current study was the large sample size of participants. Particularly, the sample size for women in the current study was larger than expected. Initially, I planned to recruit 200 female participants for this study. After data collection was complete, data from 277 female participants had been collected. Because women are less likely to enroll in STEM majors in college, I believed that it would be difficult to recruit a large number of women from these majors for the current study and expected that interpretation of results might be limited if I experienced difficulty recruiting women in these disciplines. However, the final sample included women from a variety of STEM majors, including Biology, Physics, Chemistry, Technology, and many others.

\section{Measurement Improvements}

Measuring STEM career aspirations. In the current study, improvements were made to multiple measures that were used in Christie's (2017) study. One such improvement was the change in method used to measure participants' aspirations to pursue a STEM career. Christie (2017) asked participants to rate the degree to which their intended careers involved science, technology, engineering, and mathematics, using four questions that were responded to with a Likert scale. However, the terms "technology" and "mathematics" had not been operationally defined for participants, who were free to interpret these terms (e.g., a job that uses a computer could be interpreted to include use of "technology"). Thus, participants who were not going into traditionally defined STEM careers responded that their intended careers involved a great deal of 
use of and/or training in these topics. In the current study, however, I operationally defined each of the four aspects of STEM in order to better capture training involved in careers in STEM specifically. Thus, the STEM career aspirations measure used the current study was a more accurate measure of this construct and likely more accurately reflects differences in participants aspirations to pursue careers in STEM fields.

Measuring persistence. Another improvement that was made to the measurements in the current study from Christie's (2017) study was the method used to measure persistence. Christie (2017) measured persistence using the Persistence Scale for Children (Lufi \& Cohen, 1987), and included all 40 items from the original scale. After further evaluating this scale, however, I realized that some of the items pertained to persistence in other situations (such as sports, games) that may not necessarily relate to participants' persistence in academic or career settings. My intention was to measure persistence with respect to academics in the current study. Therefore, I adapted the Persistence Scale for Children to only include items related to general persistent behavior, academic, and career behavior. I included these items to gain information about respondents' persistence in these situations, and I believe that the adapted scale was a more accurate measure of persistence as it relates to career and academic persistence than the original scale.

Measuring STEM self-efficacy. Another measure that was adapted for the current study was the math self-efficacy scale. The original scale only included items related to one's selfefficacy in math courses and everyday math tasks. Because I wanted to measure participants selfefficacy for STEM in general, and not only math, I expanded this scale to include items related to the use and application of everyday science tasks as well as self-efficacy in science courses in 
addition to math courses. By adding these items, I believe that this measure more accurately assessed overall STEM self-efficacy than the math self-efficacy scale alone would have. Predicted Models Informed by Data

Another strength of the current study was that many of the predicted relations between variables in the proposed path models were based not only on a thorough review of the literature but were also based on past data. Specifically, in the original proposed models for men and women, nearly each proposed relation in each model was based on the results of exploratory analyses from Christie's (2017) study. Although the path models in Christie's study did not include STEM self-efficacy nor inquiry learning experiences in high school science classrooms, the current study's inclusion of these variables in the proposed path models was based on a thorough review of the literature that supported how these variables might be related to other study variables.

\section{Addition of Inquiry-Based Learning Experiences}

Another way in which the current study improved upon Christie's (2017) study was through the addition of a measure of participants' IBL experiences to the exploratory models in the current study. Although Christie's study examined the role that teacher influence plays in predicting STEM career aspirations, one of the lacking aspects of this study was that it did not examine the mechanism through which teachers are influential. The current study, however, found that higher levels of inquiry learning experiences in high school science courses are predictive of higher levels of curiosity, higher levels of STEM self-efficacy, and greater aspirations to pursue a STEM career, for both men and for women. Thus, the current study has more implications for practices in schools and suggests that science teaching methods may be a key point of intervention when considering how to increase female representation in STEM 
fields. Specifically, it may be important for teachers to utilize inquiry-based teaching practices to further increase students' self-efficacy related to science subjects. The National Research Council (2011) suggests that the more science instruction is able to mimic authentic STEM practices, the more prepared for understanding the authentic nature of science students will be upon attainment of inquiry-based skills. Further, it is important that teachers not only utilize inquiry-based practices in classrooms, but they must also provide support and scaffolding for inquiry-based activities in science classrooms. Bell, Smetana, and Binns, (2005) suggest that students vary in their confidence and independence with using inquiry, including forming their own hypotheses and answering their own questions in science courses. Therefore, it may be especially important for science instructors to initially assess students' current levels of inquiry self-efficacy and independence when making decisions about levels of direct support and intervention to provide in science classrooms. Consistent with this approach, it might be beneficial to develop a measure of self-efficacy specially related to inquiry-based skills, such as investigation design and hypothesis testing.

\section{Conclusions}

In recent years, increasing emphasis has been placed on examining the factors that contribute to lower representation of women in STEM careers. Researchers have identified personal, contextual, and experiential factors that may play a role in decreasing girls' interest in science subjects as they progress through school as well as the factors that bolster interest in STEM for women throughout education. Furthermore, researchers have begun to identify the barriers that women and other underrepresented groups face throughout working towards a career in STEM and the effects that these barriers have on aspirations to stay in or leave the field. The current study was an attempt to examine the interplay between personal, contextual, and 
experiential factors over time as well as to examine differences in experienced barriers by women and men in different academic majors or fields. Results of the current study have the potential to inform both parenting practicing at home and in the community as well as teaching practices in the schools. Knowing the factors that increase women's self-efficacy in STEM in particular may be especially important for continuing to increase female representation in STEM. 


\section{REFERENCES}

Abd-El-Khalick, F., BouJaoude, S., Duschl, R., Lederman, N. G., Naaman, R. M., Hofstein, A., \& Tuan, H. L. (2004). Inquiry in science education: International perspectives. Science Education, 88, 397-419.

Ambady, N., Shih, M., Kim, A., \& Pittinsky, T. L. (2001). Stereotype susceptibility in children: Effects of identity activation on quantitative performance. Psychological Science, 12, 385-390. doi:10.1111/1467-9280.00371

Atkinson, J. W. (1957). Motivational determinants of risktaking behavior. Psychological Review, 64, 359-372. doi:10.1037/h0043445

Bachtold, L. M., \& Wemer, E. E. (1972). Personality characteristics of women scientists. Psychological Reports, 31, 391-396. doi:10.2466/pr0.1972.31.2.391

Bandura, A. (1997). Self-efficacy: The exercise of control. New York: W. H. Freeman and Company.

Barnard, W. M. (2004). Parent involvement in elementary school and educational attainment. Children and Youth Services Review, 26, 39-62. doi:10.1016/j.childyouth.2003.11.002

Becker, K., \& Kyungsuk, P. (2011). Effects of integrative approaches among science, technology, engineering, and mathematics (STEM) subjects on students' learning: A preliminary meta-analysis. Journal of STEM Education: Innovations and Research, 12, 23-37. doi:10.12691/education-2-10-4

Beilock, S. L., Gunderson, E. A., Ramirez, G., \& Levine, S. C. (2010). Female teachers' math anxiety affects girls' math achievement. Proceedings of the National Academy of Sciences of the United States of America, 107, 1860-1863. 
Bell, P., Lewenstein, B., Shouse, A. W., \& Feder, M. A. (Eds.). (2009). Learning science in informal environments. Washington, DC: National Academy Press

Bem, S. L. (1981). Gender schema theory: A cognitive account of sex typing. Psychological Review, 88, 354-364. doi:10.1037/0033-295X.88.4.354

Betz, N. E., \& Hackett, G. (1982). Development of the Mathematics Self-efficacy Scale: Extended description. Unpublished manuscript, Ohio State University, Columbus.

Blickenstaff, J. C. (2005). Women and science careers: Leaky pipeline or gender filter? Gender and Education, 17, $369-386$.

Brainard, S. G. \& Carlin, L. (1998) A six-year longitudinal study of undergraduate women in engineering and science, Journal of Engineering Education, 87, 17-27.

Bussey, K., \& Bandura, A. (1999). Social cognitive theory of gender development and differentiation. Psychological Review, 106, 676.

Campbell, T., Abd-Hamid, N. H. \& Chapman, H. (2009). Development of instruments to assess teacher and student perceptions of inquiry experiences in science classrooms. Journal of Science Teacher Education, 21, 13-30. doi:10.1007/s10972-009-9151-x

Chemers, M. M., Hu, L., \& Garcia, B. F. (2001). Academic self-efficacy and first year college student performance and adjustment. Journal of Educational Psychology, 93, 55-64.

Cheryan, S., Ziegler, S. A., Montoya, A., \& Jiang, L. (2017). Why are some STEM fields more gender balanced than others? Psychological Bulletin.

Chi, M. T. H., de Leeuw, N., Chiu, M. H., \& LaVancher, C. (1994). Eliciting self-explanations improves understanding. Cognitive Science, 18, 439-477. doi:10.1016/0364-0213(94)90016-7 
Christie, M. (2017). Predicting gender differences in intentions to pursue STEM careers.

(Unpublished master's thesis). Illinois State University, Normal, Illinois.

Corbin, J., \& Strauss, A. (2015). Basics of Qualitative Research: Techniques and Procedures for Developing Grounded Theory (4 ${ }^{\text {th }}$ ed.). Thousand Oaks, CA: Sage.

Crowley, K. D., Callanan, M. A., Jipson, J. L., Galco, J., Topping, K., \& Shrager, J. (2001). Shared scientific thinking in everyday parent-child activity. Science Education, 85, 712 732. doi:10.1002/sce.1035

Crowley, K., Callanan, M. A., Tenenbaum, H. R., \& Allen, E. (2001). Parents explain more often to boys than to girls during shared scientific thinking. Psychological Science, 12, 258-261. doi:10.1111/1467-9280.00347

Daempfle, P. A. (2003). An analysis of the high attrition rates among first year college science, math, and engineering, majors. Journal of College Student Retention, 5, 37-52. doi:10.2190/DWQT-TYA4-T20W-RCWH

Danner, F. W., \& Lonky, E. (1981). A cognitive-developmental approach to the effects of rewards on intrinsic motivation. Child Development, 52, 1043-1052. doi:10.2307/1129110

Darling-Hammond, L., \& Hudson, L. (1988). Teachers and teaching. In R. J. Shavelson, L. M. McDonnell, \& J. Oakes (Eds.), Indicators for monitoring mathematics and science education (pp. 67-95). Los Angeles, CA: Rand Corporation.

Department for Education (1994). Science and Maths: A consultation paper on the supply and demand of newly qualified young people. Department for Education.

Dick, T. P., Rallis, S. F. (1991). Factors and influences on high school students' career choices. Journal for Research in Mathematics Education, 22, 281-92. doi:10.2307/749273 
Druva, C. A., \& Anderson, R. D. (1983). Science teacher characteristics by teacher behavior and by student outcome: A meta-analysis of research. Journal of Research in Science Teaching, 20, 467-479. doi:10.1002/tea.3660200509

Duschl, R. A., Schweingruber, H. A., Shouse, A. W. Eds., Taking Science to School: Learning and Teaching Science in Grades K-8 (National Research Council, Washington, DC, 2007).

Eccles, J. S., Jacobs, J. E., \& Harold, R. (1990). Gender role stereotypes, expectancy effects, and parents' socialization of gender differences. Journal of Social Issues, 46, 183-201. doi:10.1111/j.1540-4560.1990.tb01929.x

Endsley, R. C., Hutcherson, M. A., Garner, A. P., \& Martin, M. J. (1979). Interrelationships among selected maternal behaviors, authoritarianism, and preschool children's verbal and nonverbal curiosity. Child Development, 50, 331-339. doi:10.2307/1129407

Eysenck, H. J. (1970). The Structure of Human Personality, London: Routledge

Falbo, T., Lein, L., and Amador, N. A., (2001). Parental involvement during the transition to high school, Journal of Adolescent Research, 16, 511-529. doi:10.1177/0743558401165006

Fan, X., \& Chen, M. (2001). Parental involvement and students' academic achievement: A metaanalysis. Educational Psychology Review, 13, 1-22. doi:10.1023/A:1009048817385

Fantuzzo, J., Gadsden, V., Li, F., Sproul, F., McDermott, P., Hightower, D., \& Minney, A. (2013). Multiple dimensions of family engagement in early childhood education: Evidence for a short form of the Family Involvement Questionnaire. Early Childhood Research Quarterly, 28, 734-742. doi:10.1016/j.ecresq.2013.07.001 
Fantuzzo, J., Tighe, E., \& Childs, S. (2000). Family Involvement Questionnaire: A multivariate assessment of family participation in early childhood education. Journal of School Psychology, 92, 367-376. doi:10.1037/0022-0663.92.2.367

Fast, L. A., Lewis, J. L., Bryant, M. J., Bocian, K. A., Cardullo, R. A., Rettig, M., \& Hammond, K. A. (2010). Does math self-efficacy mediate the effect of the perceived classroom environment on standardized math test performance? Journal of Educational Psychology, $102,729-740$.

Feist, G. J. (1998). A meta-analysis of personality in scientific and artistic creativity. Personality and Social Psychology Bulletin, 2, 290-309. doi: 10.1207/s15327957pspr0204_5

Field, C. B., Barros, V. R., Mach, K., \& Mastrandrea, M. (2014). Climate change 2014: impacts, adaptation, and vulnerability. 639 Contribution of Working Group II to the Fifth Assessment Report of the Intergovernmental Panel on Climate Change; 640, 2014.

Flanagan, D. P., Genshaft, J. L., \& Harrison, P. L. (2012). Contemporary intellectual assessment: Theories, tests, and issues. New York, NY: Guilford.

Fouad, N.A., Hackett, G., Smith, P.L., Kantamneni, N., Fitzpatrick, M., Haag, S., and Spencer, D. (2010). Barriers and Supports for Continuing in Mathematics and Science: Gender and Educational Level Differences. Journal of Vocational Behavior, 77, 361-373.

Fritsch, N. (2015). At the leading edge-does gender still matter? A qualitative study of prevailing obstacles and successful coping strategies in academia. Current Sociology, 63, $547-548$.

Funkhouser, J. E., \& Gonzales, M. R. (1997). Family involvement in children's education: Successful local approaches: An idea book. Washington, DC: U. S. Department of Education, Office of Educational Research and Improvement. 
George, R., \& Kaplan, D. (1998). A structural model of parent and teacher influences on science attitudes of eighth graders: Evidence from NELS:88. Science Education, 82, 93-109. doi:10.1002/(SICI)1098-237X(199801)82:1<93::AID-SCE5>3.0.CO;2-W

Gilbert, J. (2001) Science and it's 'other': looking underneath 'woman' and 'science for new directions in research on gender and science education, Gender and Education, 13, 291305.

Grolnick, W. S., \& Slowiaczek, M. L. (1994). Parents' involvement in children's schooling: A multidimensional conceptualization and motivation model. Child Development, 65, 237252. doi:10.1016/S0022-4405(00)00050-9

Grossman, J. M., \& Porche, M. V. (2014). Perceived gender and racial/ethnic barriers to STEM success. Urban Education, 49, 698-727. doi: 10.1177/0042085913481364

Gunderson, E. A., Ramirez, G., Levine, S. C., \& Beilock, S. L. (2012). The role of parents and teachers in the development of gender-related math attitudes. Sex Roles, 66, 153-166. doi:10.1007/s11199-011-9996-2

Haden, C. A. (2010). Talking about science in museums. Child Development Perspectives, 4, 62-67. doi:10.1111/j.1750-8606.2009.00119.x

Haden, C. A., Jant, E. A., Hoffman, P. C., Marcus, M., Geddes, J. R., \& Gaskins, S. (2014). Supporting family conversations and children's STEM learning in a children's museum. Early Childhood Research Quarterly, 29, 333-344. doi:10.1016/j.ecresq.2014.04.004

Harty, H., \& Beall, D. (1984). Attitudes toward science of gifted and nongifted fifth graders. Journal of Research in Science Teaching, 21, 483-488. doi:10.1002/tea.3660210505

Hebb, D. O. (1949). The origination of behavior. New York: Wiley. 
Henderson, A. (1987). The evidence continues to grow: Parent involvement improves student achievement. Columbia, MD: The National Committee for Citizens in Education.

Hill, N. E., \& Taylor, L. C. (2004). Parental school involvement and children's academic achievement_Pragmatics and issues. Current Directions in Psychological Science, 13, 161-164. doi:10.1111/j.0963-7214.2004.00298.x

Holland, J. L. (1985). Making vocational choices: A theory of vocational personalities and work environments. Englewood Cliffs, NJ: Prentice Hall.

Howe-Walsh, L., \& Turnbull, S. (2016). Barriers to women leaders in academia: tales from science and technology. Studies in Higher Education, 41, 415-428.

Huynh, V. W. (2012). Ethnic microaggressions and the depressive and somatic symptoms of Latino and Asian American adolescents. Journal of Youth and Adolescence, 41, 831-846.

Hyde, J. S. (1996) Meta-analysis and the psychology of gender differences, in: B. Laslett, S. G. Kohlstedt, H. Longino \& E. Hammonds (Eds) Gender and scientific authority (Chicago, University of Chicago Press).

Hyde, J. S., Lindberg, S. M., Linn, M. C., Ellis, A. B., \& Williams, C. C. (2008). Gender similarities characterize math performance. Science, 321, 494-495 doi:10.1126/science. 1160364

Jacobs, J. E. (1991). Influence of gender stereotypes on parent and child mathematics attitudes. Journal of Educational Psychology, 83, 518-527. doi:10.1037/0022-0663.83.4.518

Jacobs, J. E. (2005). Twenty-five years of research on gender and ethnic differences in math and science career choices: What have we learned? New Directions for Child and Adolescent Development, 110, 85-94. doi: 10.1002/cd.151 
Jirout, J., \& Klahr, D. (2012). Children's scientific curiosity: In search of an operational definition of an elusive concept. Developmental Review, 32, 125-160. doi:10.1016/j.dr.2012.04.002

Johnson, S. (1987). Gender Differences in Science: parallels in interest, experience and performance. International Journal of Science Education, 9, 467-481. doi:10.1080/0950069870090405

Jones, G., Howe, A. and Rua, M. (2000). Gender differences in students' experiences, interests, and attitudes towards science and scientists. Science Education, 84, 180-192. doi:10.1002/(SICI)1098-237X(200003)84:2<180::AID-SCE3>3.0.CO;2-X

Jones, M. G., \& Wheatley, J. (1989). Gender influences in classroom displays and studentteacher behavior. Science Education, 73, 525-545. doi:10.1002/sce.3730730503

Kahle, J. B., \& Lakes, M. K. (1983). The myth of equality in science classrooms. Journal of Research in Science Teaching, 20, 131-140. doi:10.1002/tea.3660200205

Kirchberg, V., (1998), Entrance Fees as a Subjective Barrier to Visiting Museums, Journal of Cultural Economics, 22, 1-13. doi:10.1023/A:1007452808105

Klem, A. M., \& Connell, J. P. (2004). Relationships matter: Linking teacher support to student engagement and achievement. Journal of School Health, 74, 262-273.

Kranzler, J. H., \& Pajares, F. (1997). An exploratory factor analysis of the mathematics self efficacy scale-revised (MSES-R). Measurement and Evaluation in Counseling and Development, 29, 215-228.

Kreitler, S., Zigler, E., \& Kreitler, H. (1975). The nature of curiosity in children. Journal of School Psychology, 13, 185-200. doi:10.1016/0022-4405(75)90002-3 
Larson, L. M., Pesch, K. M., Surapaneni, S., Bonitz, V. S., Wu, T. -S., \& Werbel, J. D.

(2014). Predicting graduation: The role of mathematics/science self-efficacy. Journal of Career Assessment, 1-11.

Lee, H. S., Flores, L. Y., Navarro, R. R., \& Kanagui-Muñoz, M. (2015). A longitudinal test of social cognitive career theory's academic persistence model among Latina/o and White men and women engineering students. Journal of Vocational Behavior, 88, 95-103.

Leherissey, B. L. (1971). The development of a measure of state epistemic curiosity. In H. Unal (Ed.) The influence of curiosity and spatial ability on preservice middle and secondary mathematics teachers' understanding of geometry. Unpublished doctoral dissertation. Florida: The Florida State University.

LeMoyne, T., \& Buchanan, T. (2011). Does 'hovering'” matter? Helicopter parenting and its effect on well-being. Sociological Spectrum: Mid-South Sociological Association, 31, 399-418.

Lent, R. W., Brown, S. D., \& Hackett, G. (1994). Toward a unifying social cognitive theory of career and academic interest, choice, and performance. Journal of Vocational Behavior, $45,79-122$.

Lent, R. W., Brown, S. D., \& Larkin, K. C. (1984). Relation of self-efficacy expectations to academic achievement and persistence. Journal of Counseling Psychology, 31, 356-362. doi:10.1037/0022-0167.33.3.265

Lent, R. W., Lopez, F. G., Sheu, H., \& Lopez, A. M. (2011). Social cognitive predictors of the interests and choices of computing majors: Applicability to underrepresented students. Journal of Vocational Behavior, 78, 184-192. 
Li, Q. (1999). Teachers' beliefs and gender differences in mathematics: A review. Educational Research, 41, 63-76.

Lindsey, E. W., \& Mize, J. (2001). Contextual differences in parent-child play: Implications for children's gender role development. Sex Roles, 44, 155-176.

doi:10.1023/A:1010950919451

Litman, J. A., \& Spielberger, C. D. (2003). Measuring epistemic curiosity and its diversive and specific components. Journal of Personality Assessment, 80, 75-86. doi:10.1207/S15327752JPA8001_16

Litman, J. A. (2008). Interest and deprivation factors of epistemic curiosity. Personality and Individual Differences, 44, 1585-1595. doi:10.1016/j.paid.2008.01.014

Lockwood, P., \& Kunda, Z. (1997). Superstars and me: Predicting the impact of role models on the self. Journal of Personality and Social Psychology, 73, 91-103.

Loewenstein, G. (1994). The psychology of curiosity: A review and reinterpretation. Psychological Bulletin, 116, 75-98. doi:10.1037/0033-2909.116.1.75

Lounsbury, J. W., Foster, N., Patel, H., Carmody, P., Gibson, L. W., \& Stairs, D. R. (2012). An investigation of the personality traits of scientists versus nonscientists and their relationship with career satisfaction. $R$ and $D$ Management, 42, 47-59. doi:10.1111/j.1467-9310.2011.00665.x

Lufi, D., \& Cohen, A. (1987). A scale for measuring persistence in children. Journal of Personality Assessment, 51, 178 -185. doi:10.1207/s15327752jpa5102_2

Maltese, A. V., \& Tai, R. (2011). Pipeline persistence: Examining the association of educational experiences with earned degrees in STEM among U.S. students. Science Education, 95, 877-907. doi:10.1002/sce .20441 
Maple, S. A., \& Stage, F. K. (1991). Influences on the choice of math/science major by gender and ethnicity, American Educational Research Journal, 28, 37-60. doi:10.3102/00028312028001037

Marchant-Haycox, S. E., \& Wilson, G. P. (1992). Personality and stress in performing artists. Personality and Individual Differences, 13, 1061-1068. doi:10.1016/0191-8869(92)90021-G

Markus, H., \& Oyserman, D. (1989). Gender and thought: The role of the self-concept. In M. Crawford \& M. Gentry (Eds.), Gender and thought: Psychological perspectives. (pp. 100-127). New York: Springer.

Marra, R. M., Rodgers, K. A., Shen, D. \& Bogue, B. (2009). Women engineering students and self-efficacy: A multi-year, multi-institutional study of women engineering student selfefficacy. Journal of Engineering Education, 98, 27-38.

Marsh, H. W. (1990). The structure of academic self-concept: The Marsh/Shavelson model. J. Educational Psychology, 82, 623-636.

Marx, D. M., \& Roman, J. S. (2002). Female role models: Protecting women's math test performance. Personality and Social Psychology Bulletin, 28, 1183-1193.

McCallum, M.L., \& Bury, G. W. (2013) Google search patterns suggest declining interest in the environment. Biodiversity Conservation, 22, 1355-1367. doi:10.1007/s10531-013-0476-6

McDougall, W. (1908). An introduction to social psychology. London: Methuen.

McReynolds, P., Acker, M., \& Pietila, C. (1961). Relation of object curiosity to psychological adjustment in children. Child Development, 32, 393-400. doi:10.2307/1125953

McWhirter, E. H. (1996). Teacher Support Scale (TSS). Unpublished measure. 
Metheny, J., McWhirter, E. H., \& O’Neil, M. E. (2008). Measuring perceived teacher support and its influence on adolescent career development. Journal of Career Assessment, 16, 218-237. doi:10.1177/1069072707313198

Michaels, S., Shouse, A., \& Schweingruber, H. (2008). Ready, set, science!: Putting research to work in K-8 science classrooms. Washington, D.C.: The National Academies Press.

Minuchin, P. (1971). Correlates of curiosity and exploratory behavior in preschool disadvantaged children. Child Development, 42, 939-950. doi: 10.2307/1127460

Mitchell, S. N. \& Hoff, D. L. (2006) (Dis)Interest in science: How perceptions about grades may be discouraging girls. Electronic Journal of Science Education, 11, 10-21.

Morgan, J. B. \& Hall, H. L. (1926). The measurement of persistence. Journal of Applied Psychology, 10, 180-187.

Mukherjee, B. N. (1974). A questionnaire measure of persistence disposition. Indian Journal of Psychology, 49, 263-278.

National Center for Education Statistics (2001). Postsecondary Institutions in the United States: Fall 2000 and degrees and other awards conferred 1999-2000 (Washington, DC, National Center for Education Statistics).

National Research Council. (2009). Learning science in informal environments: People, places, and pursuits. In P. Bell, B. Lewnstein, A. W. Shouse, \& M. A. Feder (Eds.), Committee on learning science in informal environments. Washington, DC: The National Academies Press.

National Research Council (2010). Exploring the Intersection of Science Education and 21st Century Skills: A Workshop Summary. Washington, DC: National Academies Press. 
National Research Council. (2012). A Framework for K-12 Science Education: Practices, Crosscutting Concepts, and Core Ideas. Washington, DC: National Academies Press. National Research Council (2014). STEM integration in K-12 education: Status, prospects, and an agenda for research. Washington: The National Academies Press.

National Science Board (NSB). (2007). A National Action Plan for Addressing the Critical Needs of the U.S. Science, Technology, Engineering, and Mathematics Education System Arlington, VA: National Science Foundation.

National Science Foundation. (2009). Women, minorities, and persons with disabilities in science and engineering: 2009 (NSF 09 - 305). Arlington, VA: NSF, Division of Science Resources Statistics.

Nisbet, M. C. and Myers, T. (2007) Twenty years of public opinion about global warming, Public Opinion Quarterly, 71, 444-70. doi:10.1093/poq/nfm031

OECD, PISA 2012 Results: What Students Know and Can Do Student Performance in Mathematics, Reading and Science (Volume I, Revised edition, February 2014), OECD Publishing, Paris (2014).

Peters, M. L. (2013). Examining the relationships among classroom climate, self-efficacy, and achievement in undergraduate mathematics: A multi-level analysis. International Journal of Science and Mathematics Education, 11, 459-480

Piaget, J. (1952). The origins of intelligence in children. New York: International University Press (Original work published 1936).

Planty, M., Kena, G., \& Hannes, G. (Eds.), (2009). The condition of education 2009 in brief (NCES Report No. 2009-082). Washington, DC: National Center for Education Statistics. Retrieved from http://nces.ed.gov/pubsearch/pubsinfo.asp?pubid=2009082 
Preckel, F., Goetz, T., Pekrun, R., \& Kleine, M. (2008). Gender differences in gifted and average-ability students: comparing girls' and boys' achievement, self-concept, interest, and motivation in mathematics. Gifted Child Quarterly, 52, 146-159. doi:10.1177/0016986208315834

President's Committee of Advisors on Science and Technology. (2010, September). Prepare and inspire: K-12 education in science, technology, engineering, and mathematics (STEM) for America’s future. Washington, DC: Government Printing Office.

Reed, K., Duncan, J. M., Lucier-Greer, M., Fixelle, C., \& Ferraro, A. J. (2016). Helicopter parenting and emerging adult self-efficacy: Implications for mental and physical health. Journal of Child and Family Studies, 25, 3136-3149.

Reis, S. M., \& Park, S. (2001). Gender differences in high-achieving students in math and science. Journal for the Education of the Gifted, 25, 52-73

Riegle-Crumb, C., Moore, C., Ramos-Wada A. (2011) Who wants to have a career in math or science? Exploring adolescents' future career aspirations by gender and race/ethnicity. Science Education, 95, 458-476. doi:10.1002/sce.20431

Riggs, I. M. (1991). Gender differences in elementary science teacher self-efficacy. In Paper presented at the Annual Meeting of the American Educational Research Association (Chicago, IL, April 3-7, 1991). ERIC Document Reproduction Service No. ED 340705.

Ryan, A. M., \& Patrick, H. (2001). The classroom social environment and changes in adolescents' motivation and engagement during middle school. American Educational Research Journal, 38, 437-460. doi:10.3102/00028312038002437

Sadker, M. \& Sadker, D. (1994) Failing at fairness: how our schools cheat girls (New York, Simon \& Schuster). 
Saxe, R. M., \& Stollak, G. E. (1971). Curiosity and the parent-child relationship. Child Development, 42, 373-384. doi:10.2307/1127473

Shapiro, J., \& Williams, A. (2011). The role of stereotype threats in undermining girls' and women's performance and interest in STEM fields. Sex Roles. New York: Springer.

Shelton, J., \& Harris, T. L. (1979). Personality characteristics of art students. Psychological Reports, 44, 949-950. doi: 10.2466/pr0.1979.44.3.949

Sonnert, G. \& Holton, G. (1995) Who succeeds in science? (New Brunswick, NJ, Rutgers University Press).

Spielberger, C. D. (1983). Manual for the state-trait anxiety inventory (form Y). Palo Alto, CA: Consulting Psychologists Press.

Sue, D. W., Capodilupo, C. M., Torino, G. C., Bucceri, J. M., Holder, A. M. B., \& Nadal, K. L. (2007). Racial microaggressions in everyday life: Implications for clinical practice. American Psychologist, 62, 271-286.

Summers, L. H. (2005). Remarks at NBER Conference on Diversifying the Science \& Engineering Workforce. Cambridge, MA, January 14, 2005. Retrieved October 5, 2017, from Harvard University, the Office of the President Web site: http://www.president.harvard.edu/speeches/2005/nber.html

Tiedemann, J. (2000). Parents' gender stereotypes and teachers' beliefs as predictors of children's concept of their mathematical ability in elementary school. Journal of Educational Psychology, 92, 144-151. doi:10.1037/0022-0663.92.1.144

Ullman, J. D. (2007). Structural equation modeling. In Tabachnick, B. G., \& Fidell, L. S. (Ed.), Using Multivaiate Statistics 5th eds. (pp. 676-780). Boston, MA: Pearson Education, Inc. 
Wigfield, A., \& Eccles, J. S. (1989). Test anxiety in elementary and secondary school students. Educational Psychologist, 24, 159-183.

Wigfield, A., Eccles, J. S., Yoon, K. S., Harold, R. D., Arbreton, A. J. A., FreedmanDoan, C., \& Blumenfeld, P. C. (1997). Change in children's competence beliefs and subjective task values across the elementary school years: A 3-year study. Developmental Psychology, $89,451-468$.

Wigfield, A., \& Meece, J. (1988). Math anxiety in elementary and secondary school students. Journal of Educational Psychology, 80, 210-216.

Wright, J. D., \& Hounshell, P. B. (1981). A survey of interest in science for participants in a junior science and humanities symposium. School Science and Mathematics, 81, 378382. doi: 10.1111/j.1949-8594.1981.tb09992.x

Xie, Y., \& Achen, A. (2009). Science on the decline? Educational outcomes of three cohorts of young Americans. Population Studies Center Research Report 09 - 684. Ann Arbor: University of Michigan, Institute for Social Research.

Yee, D. K., \& Eccles, J. S. (1988). Parent perceptions and attributions for children's math achievement. Sex Roles, 19, 317-333. doi:10.1007/BF00289840

Zimmerman, B. J. (2000). Self-efficacy: An essential motive to learn. Contemporary Educational Psychology, 25, 82-91. 


\section{APPENDIX A: TABLES}

Table A-1

Correlation Matrix for Study Variables

\begin{tabular}{lcccccccc}
\hline & 1 & 2 & 3 & 4 & 5 & 6 & 7 & 8 \\
\hline 1 Family Involvement (FIQ) & -- & $.48^{* *}$ & $-.14^{*}$ & $.20^{* *}$ & $.17^{* *}$ & $.19^{* *}$ & $.20^{* *}$ & $.19^{* *}$ \\
2 Science Experiences & $.55^{* *}$ & -- & -.07 & $.15^{*}$ & $.20^{* *}$ & $.26^{* *}$ & $.25^{* *}$ & $.23^{* *}$ \\
3 Persistence (PSC) & $-.20^{* *}$ & -.11 & -- & -.06 & -.06 & -.07 & $-.17^{* *}$ & -.09 \\
4 Curiosity (ECS) & $.28^{* *}$ & $.23^{* *}$ & $-.16^{*}$ & -- & .11 & $.35^{* *}$ & $.20^{* *}$ & $.23^{* *}$ \\
5 Math/Science Teacher Influence & $.15^{*}$ & .10 & -.12 & $.16^{*}$ & -- & $.26^{* *}$ & $.27^{* *}$ & $.36^{* *}$ \\
6 Math/Science Self-Efficacy & .02 & $.20^{* *}$ & -.02 & $.23^{* *}$ & $.36^{* *}$ & -- & $.32^{* *}$ & $.56^{* *}$ \\
7 Inquiry Learning Experiences & $.35^{* *}$ & $.30^{* *}$ & -.13 & $.21^{* *}$ & $.17^{*}$ & $.28^{* *}$ & -- & $.30^{* *}$ \\
8 STEM Career Aspirations & .10 & $.16^{*}$ & -.07 & $.21^{* *}$ & $.26^{* *}$ & $.55^{* *}$ & $.35^{* *}$ & -- \\
\hline $\boldsymbol{M}$ & 46.93 & 12.23 & 35.97 & 27.44 & 9.21 & 9.85 & 59.15 & 12.51 \\
SD & 13.59 & 3.10 & 2.50 & 5.46 & 2.37 & 2.16 & 17.18 & 3.69
\end{tabular}

Note: Correlations for men are depicted below main diagonal and correlations for women are above the main diagonal.

$* p<.05 . * * p<.01$ 
Table A-2

Measure Means and Standard Deviations

\begin{tabular}{lcccc} 
& \multicolumn{2}{c}{ Men } & \multicolumn{3}{c}{ Women } \\
\hline Scale Scores & $M$ & $S D$ & $M$ & $S D$ \\
\hline Family Involvement (FIQ-SF) & 45.75 & 13.78 & 47.68 & 13.32 \\
Science Experiences & 11.86 & 3.05 & 12.42 & 3.12 \\
Persistence (PSC) & 35.82 & 2.72 & 36.12 & 2.33 \\
Curiosity (ECS) & 26.63 & 5.46 & 27.80 & 5.25 \\
Math/Science Teacher Influence & 9.43 & 2.47 & 9.08 & 2.32 \\
Math/Science Self-Efficacy & 9.85 & 2.09 & 9.83 & 2.16 \\
Inquiry Learning Experiences & 59.74 & 16.64 & 58.90 & 17.70 \\
STEM Career Aspirations & 13.09 & 3.52 & 12.14 & 3.66 \\
\hline
\end{tabular}


Table A-3

Qualitative Response Frequencies for Past and Current Barriers

\begin{tabular}{|c|c|c|}
\hline Code & $\begin{array}{c}\text { Frequency (Past) } \\
n=130\end{array}$ & $\begin{array}{c}\text { Frequency (Current) } \\
n=339\end{array}$ \\
\hline Gender-role socialization & 0 & 3 \\
\hline Gender-Role stereotypes & 1 & 3 \\
\hline Lack of female role models/representation & 1 & 8 \\
\hline $\begin{array}{l}\text { Experience of microaggressions or explicit } \\
\text { prejudice/discrimination }\end{array}$ & 3 & 8 \\
\hline Course workload & 3 & 16 \\
\hline Course material & 7 & 30 \\
\hline Specific course listed & 7 & 28 \\
\hline $\begin{array}{l}\text { Math-related factors (anxiety, dislike, performance, } \\
\text { etc.) }\end{array}$ & 11 & 12 \\
\hline Test-taking anxiety/skills & 1 & 7 \\
\hline Poor relationships with teachers & 7 & 4 \\
\hline Inadequate teaching method/style & 0 & 7 \\
\hline Few female peers and supervisors & 2 & 7 \\
\hline Sexual harassment & 0 & 1 \\
\hline Job availability/attainment & 16 & 20 \\
\hline Not meeting requirements & 4 & 17 \\
\hline Financial capital barriers & 8 & 18 \\
\hline Social capital barriers & 0 & 1 \\
\hline Physical health/disability & 0 & 6 \\
\hline Mental health & 4 & 6 \\
\hline
\end{tabular}


Table A-3, Continued

\begin{tabular}{lcc}
\hline Code & Frequency (Past) & Frequency (Current) \\
& $n=130$ & $n=339$ \\
\hline Family barriers & 2 & 3 \\
Interpersonal issues (e.g. moving, location, marriage) & 4 & 12 \\
Lack of interest/motivation & 52 & 34 \\
Self-evaluation & 8 & 27 \\
Time management/time conflicts & 3 & 95 \\
No barriers reported & 7 & 23 \\
Too vague to code & 11 & \\
\hline
\end{tabular}

Note: No barriers reported refers to those who chose to respond to the open-ended item but specifically wrote "no barriers" (or variant) 
Table A-4

Frequency Distribution for Number of Past and Current Barriers Experienced

\begin{tabular}{lcc} 
Number of Barriers & Frequency (Past) & Frequency (Current) \\
& $n=130$ & $n=339$ \\
\hline Reported Experiencing No Barriers & 10 & 95 \\
1 Barrier Reported & 92 & 190 \\
2 Barriers Reported & 23 & 40 \\
3 Barriers Reported & 4 & 13 \\
4 Barriers Reported & 1 & 1 \\
\hline
\end{tabular}


Table A-5

Frequency Count of Participants' Current Academic Majors/Fields of Study

\begin{tabular}{|c|c|c|}
\hline Major/Field & Frequency (Male) & Frequency (Female) \\
\hline Arts (E.g., Arts, dance, music) & 4 & 15 \\
\hline Biology & 20 & 46 \\
\hline Business (E.g. Business, marketing, advertising) & 16 & 20 \\
\hline Chemistry & 3 & 6 \\
\hline Communications/Public Relations & 1 & 12 \\
\hline Computer Science/Technology & 13 & 13 \\
\hline Criminal Justice & 18 & 4 \\
\hline Education & 30 & 28 \\
\hline Engineering & 6 & 5 \\
\hline Exercise Science & 8 & 7 \\
\hline History & 13 & 18 \\
\hline Literature/English & 4 & 25 \\
\hline Math & 5 & 4 \\
\hline $\begin{array}{l}\text { Medical Sciences (E.g., pre-medicine, pre- } \\
\text { dentistry) }\end{array}$ & 4 & 10 \\
\hline Nursing & 6 & 14 \\
\hline Other Science Major (E.g., Environmental) & 4 & 6 \\
\hline Physics & 4 & 3 \\
\hline Political Science/Policy/Law & 2 & 22 \\
\hline Psychology/Sociology & 36 & 40 \\
\hline Undecided/General Studies & 5 & 2 \\
\hline
\end{tabular}

Note: Total frequency for both men and women is greater than the total sample size because some participants reported more than one major. 


\section{APPENDIX B: CHILDHOOD SCIENCE EXPERIENCES QUESTIONNAIRE}

For the following scale, we are interested in identifying specific experiences and activities that occurred during your childhood. For the 10 items listed below, please respond considering how often you visited these places or engaged in these activities BEFORE the age of 13.

1. Parks
1- Almost never
2- Occasionally
3- Often
4- Almost always

2. Zoos
1- Almost never
2- Occasionally
3- Often
4- Almost always

3. Girl Scouts or Boy Scouts
1- Almost never
2- Occasionally
3- Often
4- Almost always

4. Aquariums
1- Almost never
2- Occasionally
3- Often
4- Almost always

5. Science Fairs
1- Almost never
2- Occasionally
3- Often
4- Almost always

6. Sports Games
1- Almost never
2- Occasionally
3- Often
4- Almost always

7. Art Galleries or Museums

1- Almost never 2- Occasionally 3- Often 4- Almost always

8. Home Science Projects
1- Almost never
2- Occasionally
3- Often
4- Almost always

9. Concerts
1- Almost never
2- Occasionally
3- Often
4- Almost always

10. Science Museums
1- Almost never
2- Occasionally
3- Often
4- Almost always 


\section{APPENDIX C: MODIFIED VERSION OF THE FAMILY INVOLVEMENT QUESTIONNAIRE - SHORT FORM}

For the following scale, we are interested in identifying which experiences occurred during your childhood and adolescence. For the 21 items listed below, please respond considering how often these experiences occurred in your life BEFORE the age of 18. Please respond about the parent who was MOST involved in your school and education.

1. My parent attended conferences with the teacher to talk about my learning or behavior.
1- Never
2- Sometimes
3- Often
4- Always

2. My parent talked to my teacher about my daily school routine.
1- Never
2- Sometimes
3- Often
4- Always

3. My parent talked to my teacher about the classroom rules.
1- Never
2- Sometimes
3- Often
4- Always

4. My parent talked to the teacher about how I got along with classmates in school.
1- Never
2-Sometimes
3- Often
4- Always

5. My parent talked to my teacher about my accomplishments.
1- Never
2-Sometimes
3- Often
4- Always

6. My parent talked to my teachers about my difficulties in school.
1- Never
2-Sometimes
3- Often
4- Always

7. My parent talked with my teacher about school work I was expected to practice at home.
1- Never
2-Sometimes
3- Often
4- Always

8. My parent planned activities with the classroom teacher.
1- Never
2-Sometimes
3- Often
4- Always 
9. My parent attended parent workshops or training offered by my school.
1- Never
2- Sometimes
3- Often
4- Always

10. My parent participated in planning school trips.
1- Never
2- Sometimes
3- Often
4- Always

11. My parent volunteered in my classroom.
1- Never
2- Sometimes
3- Often
4- Always

12. My parent went on class trips with my class.
1- Never
2- Sometimes
3- Often
4- Always

13. My parent participated in parent and family social activities at my school.
1- Never
2- Sometimes
3- Often
4- Always

14. My parent talked with other parents about school meetings and events.
1- Never
2- Sometimes
3- Often
4- Always

15. My parent took me special places in the community to learn about special things (e.g. zoo, museum, etc.)
1- Never
2- Sometimes
3- Often
4- Always

16. My parent talked about my learning efforts in front of relatives and friends.
1- Never
2- Sometimes
3- Often
4- Always

17. My parent talked with me about how much they loved learning new things.
1- Never
2- Sometimes
3- Often
4- Always

18. My parent brought home learning materials for me (tapes, videos, books).
1- Never
2- Sometimes
3- Often
4- Always 
19. My parent spent time with me working on reading/writing skills.
1- Never
2- Sometimes
3- Often
4- Always

20. My parent spent time with me working on creative activities (like singing, dancing, drawing, and story-telling).
1- Never
2- Sometimes
3- Often
4- Always

21. My parent spent time with me working on number skills.

1- Never

2- Sometimes

3- Often

4- Always 


\section{APPENDIX D: EPISTEMIC CURIOSITY SCALE}

A number of statements that people use to describe themselves are given below. Read each statement and then select the appropriate response using the scale below to indicate how you generally feel. There are no right or wrong answers. Do not spend too much time on any one statement but give the answer that seems to describe how you generally feel.

1. I enjoy exploring new ideas.
1- Almost Never
2-Sometimes
3- Often
4- Almost Always

2. Difficult conceptual problems can keep me awake all night thinking about solutions.
1- Almost Never
2-Sometimes
3- Often
4- Almost Always

3. I enjoy learning about subjects that are unfamiliar to me.
1- Almost Never
2-Sometimes
3- Often
4- Almost Always

4. I can spend hours on a single problem because I just can't rest without knowing the answer.
1- Almost Never
2-Sometimes
3- Often
4- Almost Always

5. I find it fascinating to learn new information.
1- Almost Never
2-Sometimes
3- Often
4- Almost Always

6. I feel frustrated if I can't figure out the solution to a problem, so I work even harder to solve it.
1- Almost Never
2-Sometimes
3- Often
4- Almost Always

7. When I learn something new, I would like to find out more about it.
1- Almost Never
2-Sometimes
3- Often
4- Almost Always

8. I brood for a long time in an attempt to solve some fundamental problem.
1- Almost Never
2-Sometimes
3- Often
4- Almost Always

9. I enjoy discussing abstract concepts.
1- Almost Never
2-Sometimes
3- Often
4- Almost Always

10. I work like a fiend at problems that I feel must be solved.
1- Almost Never
2-Sometimes
3- Often
4- Almost Always 


\section{APPENDIX E: MODIFIED VERSION OF THE PERSISTENCE SCALE FOR CHILDREN}

Please read each statement carefully and choose the response that best indicates how you generally behave, that is, how you behave most of the time.

\begin{tabular}{|c|c|c|c|}
\hline 1 & I often do not complete many activities I begin. & YES & NO \\
\hline 2 & I usually persist in what I am doing. & YES & $\mathrm{NO}$ \\
\hline 3 & When I read a book, I do not like to take breaks until I finish it. & YES & $\mathrm{NO}$ \\
\hline 4 & $\begin{array}{l}\text { Even if I fail to solve a problem, I try again and again and hope that } \\
\text { I will find a solution. }\end{array}$ & YES & NO \\
\hline 5 & While I am doing my homework, I like to take breaks. & YES & $\mathrm{NO}$ \\
\hline 7 & When I read a book, I do not skip any pages. & YES & NO \\
\hline 7 & I need lots of encouragement in order to complete many things. & YES & NO \\
\hline 8 & I do not keep on working after the time given for the work is over. & YES & NO \\
\hline 9 & I often stay up all night to study. & YES & NO \\
\hline 10 & When I am at a party, I will stay even if it is boring. & YES & NO \\
\hline 11 & $\begin{array}{l}\text { When I do not understand something, I will ask my teacher again } \\
\text { and again until I understand. }\end{array}$ & YES & NO \\
\hline 12 & When I fail in something, I am willing to try again and again. & YES & $\mathrm{NO}$ \\
\hline 13 & $\begin{array}{l}\text { I won't try to solve a problem again and again if I don't find the } \\
\text { solution in the first time I try it. }\end{array}$ & YES & NO \\
\hline 14 & $\begin{array}{l}\text { When I do not understand something, I usually ask for an } \\
\text { explanation. }\end{array}$ & YES & NO \\
\hline 15 & Only the knowledge that I will succeed on a test makes me study. & YES & NO \\
\hline 16 & I do not stop my work even if it is very difficult. & YES & $\mathrm{NO}$ \\
\hline 17 & I will stop my work on time even if I do not finish it. & YES & $\mathrm{NO}$ \\
\hline 18 & $\begin{array}{l}\text { When I am in the classroom, I try to answer all the questions asked } \\
\text { in the class. }\end{array}$ & YES & NO \\
\hline 19 & $\begin{array}{l}\text { When I have difficulties doing something, I prefer to get help rather } \\
\text { than doing it by myself. }\end{array}$ & YES & NO \\
\hline 20 & $\begin{array}{l}\text { I study at home only when I have to be prepared for class the next } \\
\text { day. }\end{array}$ & YES & NO \\
\hline 21 & $\begin{array}{l}\text { If I was kicked out of work for no reason, I would not leave until I } \\
\text { got a proper explanation. }\end{array}$ & YES & NO \\
\hline 22 & $\begin{array}{l}\text { If I try to solve a mathematical problem, I will not stop until I find a } \\
\text { solution or a different approach. }\end{array}$ & YES & NO \\
\hline 23 & I do not persist in most of the things I do. & YES & $\mathrm{NO}$ \\
\hline 24 & I usually give up easily when I do not succeed. & YES & $\mathrm{NO}$ \\
\hline
\end{tabular}




\section{APPENDIX F: MODIFIED VERSION OF THE INFLUENCE OF ROLE-MODELS SCALE}

Please rate the degree to which each of the following people has been influential in your decision to choose and stay in your major. A person would have a "negative influence" if he/she discouraged you in some way from pursuing or staying in your major. A person would have a "positive influence" if he/she encouraged you in some way to pursue or stay in your major. A person would have a "neutral influence" if he/she neither encouraged nor discouraged you from pursuing or staying in your major. If an item does not seem to apply to you, please select "N/A".

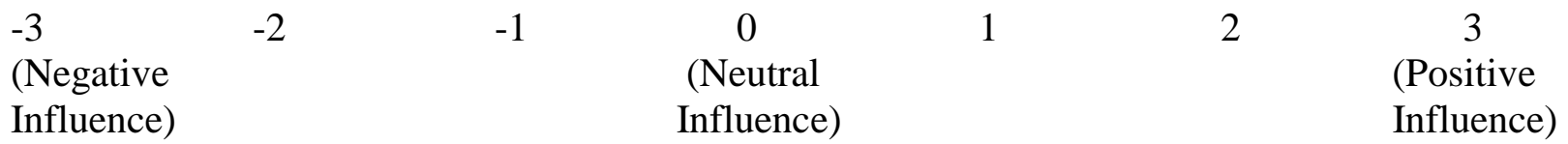

1. Mother

$-3$

$-2$

$-1$

0

1

2

3

2. Father

$-3$

$-2$

$-1$

0

2

3

3. High school math teacher(s)

$-3$

$\begin{array}{ll}-2 & -1\end{array}$

0

1

2

3

4. High school science teacher(s)

$-3$

$\begin{array}{ll}-2 & -1\end{array}$

0

1

2

3

5. High school English teacher(s)

$-3$

$\begin{array}{ll}-2 & -1\end{array}$

0

1

2

6. High school history teacher(s)

$-3$

$-2-1$

0

1

2

3

7. High school arts/music teacher(s)

0

1

2

3

8. Favorite male teacher

$-3$

$-2$

$-1$

0

1

2 
What subject did this person teach?

9. Favorite female teacher $-$

$-2-1$

$-1 \quad 0$

1

2

3

What subject did this person teach? 


\section{APPENDIX G: MODIFIED VERSION OF THE MATHEMATICS SELF-EFFICACY \\ QUESTIONNAIRE}

\section{Part I: Everyday Math Tasks}

Please indicate how much confidence you have that you could successfully accomplish each of these tasks by selecting the number according to the following 5-point confidence scale. Please respond carefully.

Confidence Scale:

$\begin{array}{llllll}1 & 2 & 3 & 4 & 5\end{array}$

No Confidence

at All

Very Little

Confidence

\section{Some} Confidence
Much
Confidence
Complete

Confidence

1. Add two large numbers (e.g., $5739+62543$ ) in your head

2. Determine the amount of sales tax on a clothing purchase.

3. Figure out how much material to buy in order to make curtains.

4. Determine how much interest you will end up paying on a $\$ 675$ loan over 2 years at $143 / 4 \%$ interest.

5. Use a scientific calculator.

6. Compute your car's gas mileage.

7. Calculate recipe quantities for a dinner for 41 when the original recipe is for 12 people.

8. Balance your checkbook without a mistake.

9. Understand how much interest you will earn on your savings account in 6 months, and how that interest is computed.

10. Figure out how long it will take to travel from City A to City B driving $55 \mathrm{mph}$.

11. Set up a monthly budget for yourself.

12. Compute your income taxes for the year.

13. Understand a graph accompanying an article on business profits.

14. Figure out how much you would save if there is a $15 \%$ markdown on an item you wish to buy.

15. Estimate your grocery bill in your head as you pick up items.

16. Figure out which of two summer jobs is the better offer; one with a higher salary but no benefits, the other with a lower salary plus room, board, and travel expenses.

17. Figure out the tip on your part of a dinner bill split 8 ways.

18. Figure out how much lumber you need to buy in order to build a set of bookshelves. 


\section{Part II: Everyday Science Tasks}

1. Estimate which direction you are facing based on the time of day and length and direction of your shadow.

2. Pick a car that would be the most fuel-efficient and cause the least environmental harm.

3. Determine whether or not an educational tutoring program was effective.

4. Evaluate the effectiveness of two medical treatments and determine which would be better to choose.

5. Identify the rising agents used in a recipe for baking a cake.

6. Write computer programming code.

7. Conduct library or internet research on a relevant topic, such as whether or not a causal link exists between pollution from a chemical plant and cancer in your area.

8. Describe the difference between correlational and experimental research studies.

9. Explain how it is possible for two brown-eyed parents to have a blue-eyed child.

10. Explain why one typically sees lighting before thunder.

11. Predict whether water heated in a city above sea level would boil faster than water heated in a city below sea level.

12. Describe the movements of an object with negative acceleration, positive acceleration, and constant velocity.

13. Describe how mountains are formed.

14. Explain why it is important that we have many large areas of forests on the planet.

15. Predict the trajectory of an object dropped from a flying airplane.

16. Describe why knowing the length of a half-life of a radioactive material is important.

17. Explain regression to the mean.

18. Describe how the ages of ancient artifacts are estimated.

\section{Part III: Courses}

Please rate the following college courses according to how much confidence you have that you could complete the course with a final grade of "A" or "B". Select your answer according to the 10-point scale below:

\section{Confidence Scale:}

\begin{tabular}{|c|c|c|c|c|}
\hline 1 & 2 & 3 & 4 & 5 \\
\hline $\begin{array}{c}\text { No Confidence } \\
\text { at All }\end{array}$ & $\begin{array}{l}\text { Very Little } \\
\text { Confidence }\end{array}$ & $\begin{array}{c}\text { Some } \\
\text { Confidence }\end{array}$ & $\begin{array}{c}\text { Much } \\
\text { Confidence }\end{array}$ & $\begin{array}{l}\text { Complete } \\
\text { Confidence }\end{array}$ \\
\hline
\end{tabular}




\section{$\underline{\text { Courses self-efficacy items }}$}

1. Basic college math

2. Economics

3. Statistics

4. Physiology

5. Calculus

6. Business administration

7. Algebra II

8. Philosophy

9. Geometry

10. Computer science

11. Accounting

12. Zoology

13. Algebra

14. Trigonometry

15. Advanced calculus

16. Biochemistry

17. Neuroscience

18. Physics

19. Pharmacology

20. Biology

21. Environmental Science
22. Mechanical Engineering

23. General Chemistry

24. Genetics

25. Biotechnology

26. Astronomy

27. Organic Chemistry

28. Computer Engineering

29. Geology

30. World History

31. Psychology

32. English Literature

33. Spanish I

34. U.S. History

35. Art

36. Creative Writing

37. Women's Studies

38. Theology

39. Sociology

40. Political Science 


\section{APPENDIX H: STEM QUESTIONNAIRE}

1. Please rate the extent to which your career/intended career involves training in/use of

A. Mathematics (Definition: the study of patterns and relationships among quantities, numbers and shapes; includes theoretical mathematics and applied mathematics).

$\begin{array}{lccc}1 & 2 & 3 & 4 \\ \text { no training/ } & & \begin{array}{l}\text { some training/ } \\ \text { use of }\end{array} & \begin{array}{l}\text { a great deal of } \\ \text { training/use of }\end{array}\end{array}$

B. Technology (Definition: comprises the entire system of people and organizations, knowledge, processes, and devices that go into creating and operating technological artifacts.)

$\begin{array}{lccc}1 & 2 & 3 & 4 \\ \text { no training/ } & \text { some training/ } & 5 \\ \text { use of } & & \begin{array}{l}\text { a great deal of } \\ \text { training/use of }\end{array}\end{array}$

C. Science (Definition: the study of the natural world, including the laws of nature associated with physics, chemistry, and biology, and the treatment or application of facts, principles, concepts, or conventions associated with these disciplines.

\begin{tabular}{lccc}
1 & 2 & \multicolumn{1}{c}{$\begin{array}{c}1 \\
\text { some training/ } \\
\text { use of }\end{array}$} & 4 \\
use of & & $\begin{array}{l}\text { a great deal of } \\
\text { training/use of }\end{array}$
\end{tabular}

D. Engineering (Definition: the design and creation of products and solving problems utilizing concepts in science and mathematics and technological tools.

$\begin{array}{lccc}1 & 2 & 3 & 4 \\ \text { no training/ } & & \begin{array}{l}\text { some training/ } \\ \text { use of }\end{array} & \begin{array}{l}\text { a great deal of } \\ \text { training/use of }\end{array}\end{array}$

2. Have you ever switched majors or career intentions? YES/NO

3. If you answered yes to the previous question, what was your previous major?

4. If you answered "yes" to question 2, please describe the barriers you encountered in your PAST major/past career

5. Please describe the barriers you have encountered, if any, in your CURRENT major/current career.

6. For how many years have you been interested in pursuing your current major/career path? 


\section{APPENDIX I: INQUIRY EXPERIENCES IN SCIENCE CLASSROOMS QUESTIONNAIRE}

Please respond to the following questionnaire about your general experiences in your science classes in high school.

\section{A. Asking questions/framing research questions:}

A1. In the science classes I have been a student in, other students and I formulated questions that then were answered through investigations.

A2. In my science classes, students' research questions were used to determine the direction and focus of lab activities.

A3. In my science classes it was important for me and other students to frame our own research questions.

A4. In my science classes, I felt that time was devoted to refining students' questions so that they could be answered through investigations.

\section{B. Designing investigations:}

B1. In my science classes, students were given step-by-step instructions before we conducted investigations.

B2. In my science classes, we designed our own procedures for investigations.

B3. In the science classes I have been a student in, students were allowed to critique and revise the procedures employed to conduct investigations.

B4. In my science classes, students were asked to justify the appropriateness of the procedures that were employed when we conducted investigations.

\section{Conducting investigations:}

C1. In the science classes I have been a student in, other students and I followed our own procedures for an investigation.

C2. In my science classes, investigations were conducted by my teachers in front of the class.

C3. In my science classes, other students and I actively participated in investigations as they were conducted. 
C4. In the science classes I have been a student in, I felt that each student had an important role to play in the investigations that were being conducted.

\section{Collecting data:}

D1. In my science classes, students determined which data to collect.

D2. In the science courses I have been a student in, students took detailed notes during each investigation along with other data that we collected.

D3. In my science classes, I felt that I understood why the data I was collecting was important.

D4. In my science classes, other students and I were able to decide when data should be collected for an investigation.

\section{E. Drawing conclusions:}

E1. In the science courses I have been a student in, students had opportunity to draw our own conclusions from investigations.

E2. In my science classes, I felt that I and other students considered a variety of ways of interpreting evidence when drawing conclusions.

E3. In my science classes, I felt that I connected my conclusions from investigations to scientific knowledge.

E4. In the science courses I have been a student in, other students and I justified our conclusions with data from our own investigations. 


\section{APPENDIX J: DEMOGRAPHICS QUESTIONNAIRE}

1. Year in college:

freshman

sophomore

junior

senior

graduate student

2. College Major:

3. Age:

4. Gender:

Male

Female

Other (e.g. transgender, gender queer), please specify:

5. Racial/Ethnic Identity:

White/Caucasian

Black/African American

Hispanic/Latino

Asian/Pacific Islander

Native American

Multi-Racial/Multi-Ethnic

Other (Please Specify):

6. What is your father's highest level of education?

7. What is your mother's highest level of education?

$$
\begin{array}{ll}
1=\text { some high school } & 5=\text { Bachelor's degree } \\
2=\text { high school } & 6=\text { some postgraduate study } \\
3=\text { some college } & 7=\text { Master's degree } \\
4=\text { Associate's degree } & 8=\text { Doctorate or professional degree }
\end{array}
$$

8. In what social class would you place your family as you were growing up?

$1=$ lower class

$2=$ working class

$3=$ lower middle class
$4=$ middle class

$5=$ upper middle class

$6=$ upper class

$7=$ Prefer not to answer 


\section{APPENDIX K: A PRIORI CODING CATEGORIES FOR QUALITATIVE ANALYSIS OF OPEN-ENDED QUESTIONS ABOUT CAREER BARRIERS}

\section{Social Barriers}

Gender role socialization $(\mathrm{S} 1)$

Gender stereotypes (S2)

Lack of female role models/representation (S3)

Experience of microaggressions (S4)

\section{Structural and Institutional Barriers}

Academic barriers

Difficult Class (Prerequisite/essential) *if specified, note which course(s)

Course Workload (I1)

Course Material (I2)

Math performance anxiety (I3)

Test tasking anxiety/skills (I4)

Poor relationships with teachers (I5)

Inadequate teaching methods/style (I6)

Workplace barriers

Few female peers and supervisors (I7)

Sexual harassment (I8)

Job Availability/Attainment (I9)

\section{Socioeconomic Status Barriers}

Financial Capital Barriers (E1)

Social Capital Barriers (E2) 


\section{APPENDIX L: FINAL CODING SCHEME}

*Indicates new coding categories that were added to the original coding scheme

\begin{tabular}{|c|c|}
\hline Past/Current Barrier Codes & Prototypical Example (Participant \#, barrier type) \\
\hline \multicolumn{2}{|l|}{ Social Barriers } \\
\hline S1. Gender Role Socialization & $\begin{array}{l}\text { Pursuing career in orthopedics with MD - have had } \\
\text { occasional sexist comments by attending physicians } \\
\text { and questions as to strength and ability compared to } \\
\text { male students ( } 45 \text {, current) }\end{array}$ \\
\hline S2. Gender Stereotypes & $\begin{array}{l}\text { A majority of them view me as less competent } \\
\text { simply for being a woman (188, current) }\end{array}$ \\
\hline $\begin{array}{l}\text { S3. Lack of Female Role Models/Female } \\
\text { Representation }\end{array}$ & $\begin{array}{l}\text { You needed an (unofficial) mentor to succeed/get } \\
\text { opportunities/advocate for you with the dean/admin, } \\
\text { and all the available ones were men and rarely took } \\
\text { on female students (80, past) }\end{array}$ \\
\hline $\begin{array}{l}\text { S4. Experience of Microaggressions or Explicit } \\
\text { Prejudice/Discrimination }\end{array}$ & A lot of discrimination (397, past) \\
\hline \multicolumn{2}{|c|}{ Structural and Institutional Barriers (Academic/Workplace) } \\
\hline I1. Course Workload & Workload and study balance (448, past) \\
\hline I2. Course Material & $\begin{array}{l}\text { Harder classes when comparing to friends in other } \\
\text { majors }(154, \text { current) }\end{array}$ \\
\hline I3. Specific Course & $\begin{array}{l}\text { Calculus (192, current) } \\
\text { Organic and biochemistry (308, current) }\end{array}$ \\
\hline $\begin{array}{l}\text { I4. Math-Related Factors (anxiety, dislike, } \\
\text { performance, etc.) }\end{array}$ & Too much math $(53$, past $)$ \\
\hline I5. Test Tasking Anxiety/Test Taking Skills & Test anxiety (304, current) \\
\hline I6. Poor Relationship with Teacher/Professor & $\begin{array}{l}\text { My first doctoral advisor was emotionally abusive ( } 7 \text {, } \\
\text { current) }\end{array}$ \\
\hline I7. Inadequate Teaching Methods/Style & $\begin{array}{l}\text { It's boring, and some of the faculty is not helpful } \\
\text { (sic). }(468, \text { current) }\end{array}$ \\
\hline I8. Few Female Peers and Supervisors & $\begin{array}{l}\text { Being a woman in computer science can be a bit } \\
\text { alienating because of all the males in the major/field. } \\
\text { ( } 78 \text {, current) }\end{array}$ \\
\hline I9. Sexual Harassment & $\begin{array}{l}\text { I have also encountered sexual harassment and other } \\
\text { sex-based harassment from men in the field (167, } \\
\text { current). }\end{array}$ \\
\hline I10. Job Availability/Attainment & Not enough jobs in the field (457, past) \\
\hline $\begin{array}{l}\text { * I11. Not Meeting Requirements (for graduate } \\
\text { school, GPA) }\end{array}$ & Was unable to meet certain qualifications (221, past) \\
\hline
\end{tabular}




\section{Socioeconomic Status Barriers}

\begin{tabular}{|l|l|}
\hline E1. Financial Capital Barriers & $\begin{array}{l}\text { The cost of university }(208, \text { current }) \\
\text { How do you make money? }(230, \text { past })\end{array}$ \\
\hline E2. Social Capital Barriers & First generation college student (364, current) \\
\hline
\end{tabular}

\section{* Personal Barriers}

\begin{tabular}{|l|l|}
\hline P1. Physical Health/Disability (P1) & Tendinitis (130, current) \\
\hline P2. Mental Health & $\begin{array}{l}\text { Mental health problems - depression, anxiety (321, } \\
\text { current) }\end{array}$ \\
\hline $\begin{array}{l}\text { P3. Family Barriers (e.g., support/lack of } \\
\text { support) }\end{array}$ & $\begin{array}{l}\text { My mother absolutely hates my major. She is so } \\
\text { passive aggressive about it and irritating. I do well } \\
\text { and it never seems to be enough (122, current) }\end{array}$ \\
\hline $\begin{array}{l}\text { P4. Interpersonal Issues (e.g., moving, } \\
\text { location, marriage) }\end{array}$ & Transferring schools (410, current) \\
\hline $\begin{array}{l}\text { P5. Lack of Interest/Motivation (includes } \\
\text { indecisiveness) }\end{array}$ & $\begin{array}{l}\text { I did not like it as much as I thought I would (50, } \\
\text { past) }\end{array}$ \\
\hline $\begin{array}{l}\text { P6. Self-Evaluation (self-doubt, lack of } \\
\text { confidence) }\end{array}$ & I am barely smart enough (168, current) \\
\hline \begin{tabular}{l} 
P7. Time Management/Time Conflicts \\
\hline
\end{tabular} & Work and school balance (171, current) \\
\hline V1. Too vague to code & Quantity and variety of information (141, current) \\
\hline
\end{tabular}

